\title{
Fluid-phase and membrane markers reveal spatio-temporal dynamics of membrane traffic and repair in the green alga Chara australis
}

\author{
Aniela Sommer ${ }^{1} \cdot$ Margit Hoeftberger $^{1} \cdot$ Ilse Foissner $^{1}$ (D) \\ Received: 25 May 2020 / Accepted: 5 October 2020 / Published online: 11 March 2021 \\ (C) The Author(s) 2021
}

\begin{abstract}
We investigated the mechanisms and the spatio-temporal dynamics of fluid-phase and membrane internalization in the green alga Chara australis using fluorescent hydrazides markers alone, or in conjunction with styryl dyes. Using live-cell imaging, immunofluorescence and inhibitor studies we revealed that both fluid-phase and membrane dyes were actively taken up into the cytoplasm by clathrin-mediated endocytosis and stained various classes of endosomes including brefeldin A- and wortmanninsensitive organelles (trans-Golgi network and multivesicular bodies). Uptake of fluorescent hydrazides was poorly sensitive to cytochalasin D, suggesting that actin plays a minor role in constitutive endocytosis in Chara internodal cells. Sequential pulselabelling experiments revealed novel aspects of the temporal progression of endosomes in Chara internodal cells. The internalized fluid-phase marker distributed to early compartments within $10 \mathrm{~min}$ from dye exposure and after about $30 \mathrm{~min}$, it was found almost exclusively in late endocytic compartments. Notably, fluid cargo consecutively internalized at time intervals of more than $1 \mathrm{~h}$, was not targeted to the same vesicular structures, but was sorted into distinct late compartments. We further found that fluorescent hydrazide dyes distributed not only to rapidly recycling endosomes but also to long-lived compartments that participated in plasma membrane repair after local laser injury. Our approach highlights the benefits of combining different fluid-phase markers in conjunction with membrane dyes in simultaneous and sequential application modus for investigating vesicle traffic, especially in organisms, which are still refractory to genetic transformation like characean algae.
\end{abstract}

Keywords Alexa 488 hydrazide $\cdot$ Chara internodal cell $\cdot$ FM4-64 $\cdot$ Live-cell imaging $\cdot$ Endocytosis markers $\cdot$ Fluid-phase endocytosis · Plant endocytosis

\section{Introduction}

Eukaryotic cells internalize plasma membrane and extracellular material by endocytosis. During this process, the plasma membrane produces an invagination, which pinches off to form an endocytic vesicle. Endocytic vesicles then fuse with each other and with other organelles for degradation of membranes and vesicle contents, and for recycling. Endocytosis is

Handling Editor: Liwen Jiang

Aniela Sommer

aniela.sommer@gmx.at

Ilse Foissner

ilse.foissner@sbg.ac.at

1 Department of Biosciences, University of Salzburg, Hellbrunnerstr. 34, 5020 Salzburg, Austria not only important for the recycling of plasma membrane components and for nutrient uptake, but also for signaling in animal and plant cells (see Geldner et al. 2007; Doherty and McMahon 2009; Irani and Russinova 2009; Baisa et al. 2013; and references therein). Our knowledge about endocytosis in general is largely derived from animal and fungal cells, in which a variety of endocytic pathways have been described. In recent years, much progress was made also in plant cell research, with the introduction of fluorescent dyes as endocytic tracers, and with the development of new molecular biological techniques (for recent reviews see Reynolds et al. 2018; Rosquete et al. 2018; Rodriguez-Furlan et al. 2019).

Endocytosis can be classified according to the cargo (e. g. receptor-mediated endocytosis and fluid phase endocytosis FPE, including uptake of assimilates or nutrients), or according to the mechanism of endocytosis, i. e. the machinery which is used to form an endocytic vesicle from the plasma membrane (Doherty and McMahon 2009; Lundmark and 
Carlsson 2010). Receptor-mediated endocytosis and fluidphase endocytosis do not exclude each other, and receptordependent endocytosis has often been found to be accompanied by uptake of extracellular cargo (Bandmann et al. 2014). Furthermore, most cargos can enter by several pathways, and it has therefore been suggested to distinguish endocytosis according to their differential dependence on certain lipids and proteins (Doherty and McMahon 2009). Among these, clathrin-mediated endocytosis is best defined and involves membrane curvature by clathrin triskelions, followed by dynamin-mediated membrane fission (Lundmark and Carlsson 2010). Coated pits and coated vesicles at or near the plasma membrane of plant cells, including characean internodes (Pickett-Heaps 1967) have been observed on electron microscopical sections already in the 1960s (see Newcomb 1980 for further references), and later research confirmed the existence of clathrin-dependent endocytosis in plant cells (e.g. Baisa et al. 2013 and references therein). Contradictory data exist about the requirement for actin or microtubules in clathrin-mediated endocytosis (Baisa et al. 2013; Narasimhan et al. 2020). Alternative, clathrin-independent endocytic pathways have also been reported in plant cells (e.g. Grebe et al. 2003; Moscatelli et al. 2007; Onelli et al. 2008; Boutte and Grebe 2009; Bandmann and Homann 2012; Baral et al. 2015, review by Fan et al. 2015). Most of these pathways are likely to be sterol-dependent, but more research is required for elucidating the mechanism by which endocytic vesicles are formed and recognize their target organelles.

The process of endocytosis can be followed in vivo with the fluorescence or confocal laser scanning microscope, using plasma membrane markers or fluid-phase dyes which are taken up together with the extracellular medium. Among the membrane markers, FM styryl dyes are the most frequently used, although possible side effects should be considered (Meckel et al. 2004; Jelinkova et al. 2010). These dyes incorporate into the plasma membrane via a hydrophobic hydrocarbon tail, whereas their hydrophilic head group prevents passage across membranes. Time-course studies showed early co-localization of FM-dye signal with TGN specific markers, suggesting that after uncoating, the endocytic vesicles fuse firstly with the TGN, the early endosome in plant cells (Dettmer et al. 2006; Foissner and Wasteneys 2007). From there, the FM-styryl dye is further distributed to MVBs, and finally becomes part of the lytic vacuole membrane. In-depth studies using endocytic organelle- or cargo-specific markers are however only possible in and restricted to organisms that can easily be genetically transformed.

The endocytic uptake of external medium in intact plant cells can be followed using fluorescent markers that are plasma membrane impermeant, but are able to pass through the cell wall. Fluorescent hydrazides were introduced as fluidphase markers for plant cell endocytosis by Oparka and coworkers (Oparka 1991). Meanwhile, fluorescent dextrans,
Coro-Na, fluorescein isothiocyanate labelled-bovine serum albumin and Alexa hydrazides were also successfully applied to study the uptake of extracellular fluid by heterotrophic, walled plant cells (Emans et al. 2002; Etxeberria et al. 2006, 2007a, b, 2012; Gall et al. 2010; Adlassnig et al. 2012; Bandmann et al. 2014).

A wide variety of heterotrophic plant cells and tissues was reported to use FPE as a distinct, clathrin-independent mechanism for the uptake of nutrients, extracellular matrix components and sugar analogs (Etxeberria et al. 2012), yet a detailed characterization of this endocytic pathway is still missing. Comparatively little is known about the role of FPE in autotrophic cells, where uptake of nutrients from the cell exterior is less important, but FPE might be required for other cellular processes like cell wall homeostasis, plasma membrane recycling and heavy metal uptake and sequestration (Baluska et al. 2005; Illes et al. 2006; Wang et al. 2014).

In the current study, we investigated the mechanisms (clathrin-dependent or not) and the spatio-temporal dynamics of fluid-phase and membrane internalization in internodal cells of the branched, multi-cellular green alga Chara australis, with focus on FPE. We conducted pulse-chase experiments with fluorescent hydrazides as extracellular medium markers alone or in conjunction with FM styryl dyes, applied simultaneously or consecutively, and followed their spatio-temporal distribution to target organelles. Immunofluorescence and pharmacological tools as well as metabolic inhibitors were used in order to identify the endosomal compartments and, respectively, to unravel the uptake and internalization mechanisms involved in the endocytic pathway of Chara.

\section{Materials and methods}

\section{Algal material, culture conditions and inhibitor treatments}

Chara australis was grown in 10-50 1 aquaria in a layer of soil, peat, and sand overlaid with distilled water, at a temperature of about $20^{\circ} \mathrm{C}$ and a $16 / 8 \mathrm{~h} \mathrm{light/dark} \mathrm{cycle} \mathrm{provided} \mathrm{by} \mathrm{fluores-}$ cent lamps. Light intensity was low (about $5 \mu \mathrm{M}_{\mathrm{m}} \mathrm{m}^{-2} . \mathrm{s}^{-1}$ at the water surface) in order to prevent growth of epiphytes. Several weeks old, fully developed branchlets (side branches with limited growth) were clipped off from the 1 st to the $3 \mathrm{rd}$ whorl, and left in artificial fresh water $\left(10^{-4} \mathrm{M} \mathrm{NaCl}, 10^{-4} \mathrm{M} \mathrm{KCl}\right.$, $10^{-3} \mathrm{M} \mathrm{CaCl}_{2}$, pH 5.6) until use. They generally consisted of one or two adjacent cells of 5-20 mm length.

Inhibitor stock solutions were: cytochalasin D (Sigma Aldrich, St. Louis, MO, USA; $10 \mathrm{mM}$ in dimethyl sulfoxide (DMSO)), ikarugamycin (Santa Cruz Biotechnology, California, USA; $10 \mathrm{mM}$ in DMSO), methyl - $\beta$-cyclodextrin (Sigma Aldrich; $20 \mathrm{mM}$ in distilled water), wortmannin (Enzo 
Life Sciences, Lausen, Switzerland; $5 \mathrm{mM}$ in DMSO), brefeldin A (BFA; Sigma Aldrich; $70 \mathrm{mM}$ in DMSO). Working solutions were prepared by dilution with artificial fresh water. The cells in control groups were treated with the equivalent amounts of DMSO. The $\mathrm{pH}$ of artificial fresh water was not significantly altered by addition of the inhibitors.

\section{In vivo staining with endocytosis markers and acidotropic dyes}

As fluid-phase markers we used Alexa Fluor ${ }^{\circledR} 488$ hydrazide (Alexa 488 hydrazide, AF488HA), Alexa Fluor®568 hydrazide (Alexa 568 hydrazide, AF568HA) (both from Invitrogen, Carlsbad, CA, USA; $10 \mathrm{mM}$ stock solution in distilled water) and Lucifer Yellow CH (Sigma Aldrich; $100 \mathrm{mM}$ stock in distilled water). Working solutions were prepared by dilution with artificial fresh water. For in vivo staining of the plasma membrane, internodal cells were pulse-labeled for $5 \mathrm{~min}$ with the red fluorescent styryl dye FM4-64 (N-(3triethylammoniumpropyl)-4-(6-(4-(diethylamino) phenyl)hexatrienyl)pyridinium dibromide; Invitrogen, Carlsbad, CA, USA) at a concentration of $10 \mu \mathrm{M}$ diluted from a $500 \mu \mathrm{M}$ stock solution in distilled water. Staining of acidic compartments was performed with $10 \mu \mathrm{M}$ acidotropic dye Lysotracker Red DND-99 (Invitrogen; 1 mM stock solution in DMSO). The pulse-labelling experiments were performed at room temperature, unless otherwise stated.

\section{Confocal laser imaging, data collection and endocytosis quantification}

The confocal imaging was performed on a Leica TCS SP5 laser scanning microscope coupled to an inverted microscope (Mannheim, Germany). For image acquisition a $63 \mathrm{x}$ water immersion objective with a numerical aperture of 1.2 was used, and the pinhole size was set to 1 airy unit. For doublestained samples we always used the bidirectional, sequential scanning mode. The frame rate was typically $400 \mathrm{~Hz}$ at $512 \mathrm{x}$ 512 image size, but occasionally, for cells with very high rates of cytoplasmic streaming, a frame rate of $700 \mathrm{~Hz}$ or $1400 \mathrm{~Hz}$ and smaller image size were necessary. For the excitation of AF488HA we used the $488 \mathrm{~nm}$ line of an argon laser and the emitted fluorescence was detected in the range $505-550 \mathrm{~nm}$. Lucifer Yellow fluorescence was excited by the $405 \mathrm{~nm}$ line of a solid state laser and detected between 480 and $570 \mathrm{~nm}$. The red fluorescent styryl dye FM4-64 was excited at $514 \mathrm{~nm}$ and the fluorescent signal was detected between 660 and 720 $\mathrm{nm}$. AF568HA and Lysotracker Red were each excited with a diode pumped solid state laser at $561 \mathrm{~nm}$ and detected in the range 580-620 $\mathrm{nm}$ and 580-674 $\mathrm{nm}$, respectively.

The in vivo detection and counting of stained endosomal structures in characean internodal cells is hampered by the strong autofluorescence of the compact chloroplast files.
Therefore, we applied the "window technique", which is generally used for light microscopy observation of the endoplasm in characean cells (Kamitsubo 1972). This method consists in strong local illumination of the cells, which results in chloroplasts bleaching, swelling and eventually detaching from the irradiated area. Chara cells used in our experiments were locally irradiated with the blue light of a halide microscope lamp for $3 \mathrm{~min}$ at least one day prior to the experiments. The resulting rectangular chloroplast-free window had a size of ca. $200 \times 150 \mu \mathrm{m}$.

Local irradiation with high laser intensity (488 $\mathrm{nm}$ line of the Argon laser operated at $100 \%$ for $1 \mathrm{~min}$ and guided through a $63 \mathrm{x}$ water immersion objective) was used to study the participation of fluorescently labeled organelles in wound healing. The irradiated area had size of about $40 \times 40 \mu \mathrm{m}$. Laser irradiation at this wavelength, as also shown in studies on animal cells (Howard et al. 2011; Marg et al. 2012; Davenport et al. 2016), inflicted damage mainly on the plasma membrane whereas UV light, used for window formation, induces more extensive injury and chloroplast detachment.

Data were collected from series of individual time-lapse frames at least $1.3 \mathrm{~s}$ apart, showing fluorescent spots dispersed in the streaming cytoplasm. Images were processed with ImageJ (http://imagej.nih.gov/ij). For the quantitative analysis of endocytosis, the fluorescent particles in each frame and each channel were identified by eye and the number per area was manually counted (Choi et al. 2013; Chaparro-Garcia et al. 2015) using the Cell Counter plug-in. In order to obtain representative data sets, cumulated areas of at least $10000 \mathrm{\mu m}^{2}$ were scored for each cell. Care was taken to analyze non-overlapping regions of the cytoplasm. The Pearson-Spearman correlation (PSC) plugin of ImageJ (French et al. 2008) was used for the co-localization analysis.

Further data processing, plots and statistical analysis were performed with Sigma Plot 13 (Systat Software, San Jose, USA). Differences between mean values were tested for statistical significance $(P<0.05)$ with the Mann-Whitney rank sum test or Student's $t$-test.

\section{Immunofluorescence}

The fixation and staining steps for indirect immunofluorescence used in this study are described in detail in Schmoelzer et al. (2011). As primary antibodies we used either rabbit polyclonal anti-OsSCAMP1 as bona fide TGN specific marker (Lam et al. 2007) generously provided by Liwen Jiang, University of Hong Kong, at a concentration of $40 \mu \mathrm{g}$ per ml or a rabbit polyclonal anti-CaARA7 (GenScript; Piscataway, NJ, USA), as MVB marker at a concentration of $3.6 \mu \mathrm{g}$ per $\mathrm{ml}$ (Hoepflinger et al. 2015). The secondary antibody was in both cases an anti-rabbit IgG Alexa Fluor®546 (Invitrogen) diluted 1:200. 


\section{Electron microscopy}

Cells processed for electron microscopy were treated with wortmannin $(50 \mu \mathrm{M}$ for $2 \mathrm{~h}$ or $25 \mu \mathrm{M}$ for $30 \mathrm{~min})$, BFA (200 $\mathrm{\mu M}$ for $30 \mathrm{~min}$ ) or DMSO ( $1 \%$ for $2 \mathrm{~h}$, controls). Cells recovering for $2 \mathrm{~h}$ from a $30 \mathrm{~min}$ treatment with $25 \mu \mathrm{M}$ wortmannin were also investigated.

Since mature internodal cells of $C$. australis are too large for high pressure freezing, chemical fixation was applied as described in Foissner (1991). Briefly, branchlet internodal cells were fixed for $20 \mathrm{~min}$ at room temperature in $1 \%$ glutaraldehyde dissolved in phosphate buffer, $\mathrm{pH}$ 6.8. After several washes in buffer, cells were postfixed overnight at $4^{\circ} \mathrm{C}$ in $2 \% \mathrm{OsO}_{4}$ dissolved in buffer. Then the cells were dehydrated in an ethanol series at $4^{\circ} \mathrm{C}$, and embedded in Agar low viscosity resin (Agar Scientific, Essex, Great Britain) via propylene oxide at room temperature.

Ultrathin sections were stained with uranyl acetate and lead citrate, and micrographs were taken at elastic bright-field mode with a LEO 912 transmission electron microscope equipped with in-column energy filter (Zeiss, Oberkochen, Germany).

\section{Results}

\section{Time and concentration dependent internalization of FPE-markers in Chara}

In order to study fluid-phase uptake in the multicellular green alga Chara australis, the fluorescent hydrazide dyes AF488HA, AF568HA and Lucifer Yellow were tested, and the optimal experimental conditions for their use were identified. Our experiments were performed with internodal cells of the branchlets which have a length of up to $2 \mathrm{~cm}$ and which are thus more convenient for life cell imaging than the up to $20 \mathrm{~cm}$ long internodal cells of the main axis.

Chara cells were incubated with AF488HA at concentrations between $10 \mu \mathrm{M}$ and $4 \mathrm{mM}$, and dye uptake was followed in pulse-chase experiments, using different time combinations. After $10 \mathrm{~min}$ incubation with $4 \mathrm{mM}$ AF488HA, conspicuous "cloudy" patterns became visible in the cell wall (Fig. 1a-c). When the cells were imaged in the staining solution (2 mM AF488HA), punctate or elongate immobile structures in the cortical cytoplasm (Fig. 1d-f) could be detected, which were similar in size and shape to the complex plasma membrane convolutions known as charasomes (Franceschi and Lucas 1980; Schmoelzer et al. 2011). Indeed, these structures co-labeled with the membrane-specific red fluorescent dye FM4-64 (Fig. 1g-j) indicating that AF488HA had access to and stained the extracellular (periplasmic) space of the charasomes. Staining of the periplasmic space disappeared after a 10 min washing step in dye-free medium, whereas residual staining of the cell wall persisted even after washout times up to $48 \mathrm{~h}$.

The cytoplasm of the characean internodal cells comprises a stationary cortex with immobile chloroplasts arranged in parallel, helical files, and a motile phase (the endoplasm) which streams with high velocity (up to $100 \mu \mathrm{m} \mathrm{s}^{-1}$ ) (Video S1; Foissner and Wasteneys 2014). In the present study we were able to detect and analyze endocytic structures situated in the flowing endoplasm, beneath the chloroplast-free "windows" (see Materials and Methods), but the detection of AF488HA-containing vesicles in the cortical cytoplasm was impeded by the residual dye fluorescence in the cell wall.

The number of fluorescently labeled endoplasmic structures depended on AF488HA concentration, on the incubation time, and on temperature. The minimum dye concentration necessary for the detection of motile fluorescent spots after a $10 \mathrm{~min}$ pulse was $500 \mu \mathrm{M}$, in which case very few particles, hardly visible above the background began to appear after ca. $15 \mathrm{~min}$. At the highest dye concentration used (4 mM), and the same pulse duration, the number of fluorescent spots was noticeably higher. However, the high background staining of the cell wall limited the detection and the quantification accuracy. Therefore, a 10 min pulse with $2 \mathrm{mM} \mathrm{AH} 488 \mathrm{HA}$, followed by $10 \mathrm{~min}$ washout in dye-free medium proved to be a good compromise, that enabled a good detectability of endocytic compartments, while minimizing the disturbing fluorescence of the cell wall, and was used in most of the experiments presented here. In intact guard cells of Vicia faba the lowest AF488HA concentration that allowed in situ observation of endocytic vesicles was $4 \mathrm{mM}$ (Gall et al. 2010), which is 8 times higher than the concentration limit found by us. A likely explanation lies in the different cell-specific turgor pressures, since fluid-phase endocytosis must always overcome this barrier. The cells of open stomata have the highest known turgor, with values up to $4.5 \mathrm{MPa}$ (Meckel et al. 2004), whereas in Chara cells the value is considerably lower (0.6 MPa; Shepherd et al. 2001).

When we chased the marker 10 to 20 min after pulsing, fluorescent structures with sizes from $282 \mathrm{~nm}$ to $1100 \mathrm{~nm}$ (average diameter $496 \pm 16 \mathrm{~nm}$ ) appeared in the flowing cytoplasm (Fig. 2a). These values are rough size estimates, which might not reflect accurately the real endosome dimensions, since we cannot exclude that small particle aggregates that moved with the same velocity were seen as individual endosomes. The number of fluorescent mobile structures per $\mu \mathrm{m}^{2}$, used here as a parameter to quantify fluid-phase endocytosis, increased significantly with longer incubation times (see abundant fluorescent organelles in Video S2 after $5 \mathrm{~h}$ incubation) and longer chasing times (Fig. 2b, c). The increase observed after a chasing time of $24 \mathrm{~h}$ was surprising. We assume that a continuous, slow accumulation of AF488HA might have taken place in some endocytic compartments, that gradually received the dye by repeatedly fusing with small 

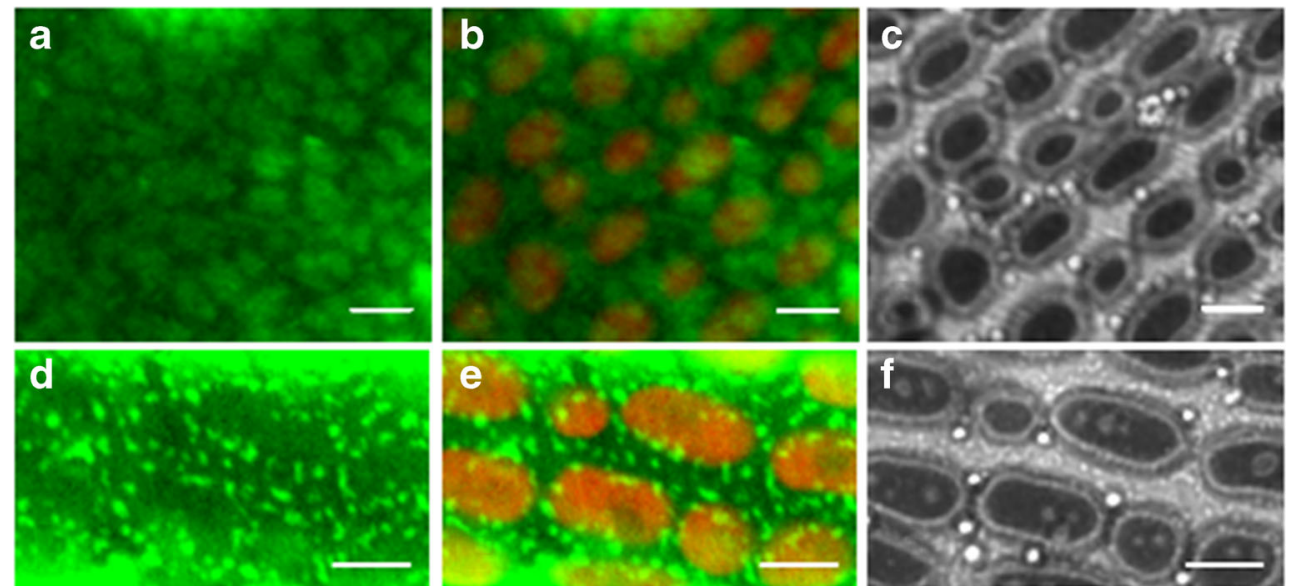
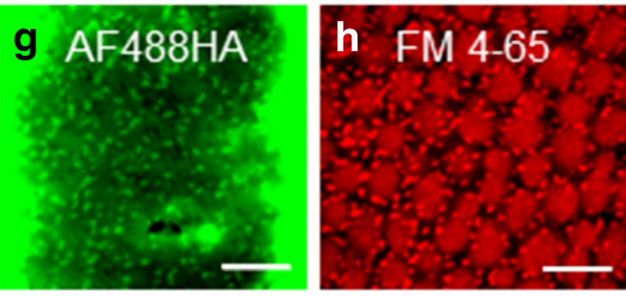

Fig. 1 Chara cell wall and periplasmic space are stained by AF488HA. a-c Cloudy fluorescent pattern in the cell wall after 10 min-incubation with $4 \mathrm{mM}$ AF488HA (a), AF488HA fluorescence merged with red autofluorescence of chloroplasts (b); (c) is the corresponding bright field image. d-f Punctate structures in the peripheral cytoplasm of a cell microscopied in $2 \mathrm{mM}$ AF488HA (d). The AF488HA fluorescence is merged with autofluorescent chloroplasts in (e); the corresponding bright

and/or insufficiently labeled and thus invisible vesicles. In addition, the cell wall space might have served as a dye reservoir over the long term.

Whereas some reports on fluid-phase endocytosis in plant cells identified the vacuole as the final destination organelle (Oparka and Prior 1988; Robinson and Milliner 1990; Oparka 1991; Etxeberria et al. 2005), others did not find the external fluid marker in this compartment (Baluska et al. 2004). We followed the distribution of the internalized dye over two days, but we could detect AH488HA fluorescence neither in the central vacuole, nor in smaller vacuoles located in the cytoplasm. Intriguingly, bright fluorescent particles were still present in the streaming endoplasm up to $48 \mathrm{~h}$ after the pulsestaining (Fig. 2b), which suggests that the fluid-phase marker was sequestered within compartments with a slow turnover rate. We further examined the internalization of the AH488HA under low temperature conditions in order to test whether the uptake could be inhibited by cold. The cells $(n=7)$ were preconditioned by incubation at $4^{\circ} \mathrm{C}$ for $10 \mathrm{~min}$ before dye addition, then exposed to $2 \mathrm{mM} \mathrm{AF} 488 \mathrm{HA}$ for $45 \mathrm{~min}$ on ice, and subsequently suspended in ice-cold dye-free medium. Immediate inspection under the confocal microscope revealed no visible particulate staining of the cytoplasm, which demonstrated that uptake of fluid-phase is an active, energy using process, in accordance with previous reports (Etxeberria et al. 2007a, 2012; Onelli et al. 2008). The low temperature

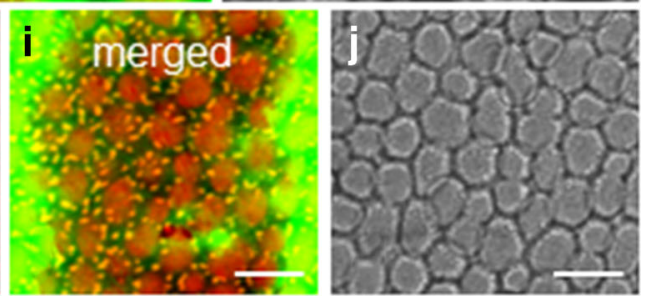

field image is shown in (f). g-j Double staining with 2 mM AF488HA (g) and the membrane-specific marker FM4-64 (h; $10 \mu \mathrm{M}, 5$ min pulsestaining); note also the red autofluorescence of the larger chloroplasts. The overlay (i) indicates that the structures stained by AF488HA correspond to the periplasmic space inside charasomes; (j) is the corresponding bright field image. Cells in (d-j) were imaged in AF488HA staining solution. Bars are $5 \mu \mathrm{m}(\mathbf{a}-\mathbf{f})$ and $10 \mu \mathrm{m}(\mathbf{g}-\mathbf{j})$

inhibition proved to be reversible, as the number of fluorescent particles in the cytoplasm increased linearly with time during adaptation to room temperature (Fig. 2c).

We next tested the red fluorescent fluid-phase marker AH568HA. It has the same net charge as AH488HA, a similar molecular brightness $\left(60.72 \mathrm{mM}^{-1} \mathrm{~cm}^{-1}\right.$, as compared to 67.16 $\mathrm{mM}^{-1} \mathrm{~cm}^{-1}$ for AH488HA; values calculated as molar extinction coefficient - quantum yield using data from www. invitrogen.com), but a higher molecular weight $\left(\mathrm{MW}_{\mathrm{AF} 568 \mathrm{HA}}=730.74 \mathrm{vs}\right.$. $\left.\mathrm{MW}_{\mathrm{AF} 488 \mathrm{HA}}=570.48\right)$ and consequently a larger Stokes radius. Under incubation conditions established to be optimal for AF488HA ( $2 \mathrm{mM}$ and $10 \mathrm{~min}$ pulse), very few fluorescent structures were visible in the cytoplasm of Chara cells when using AH568HA. In order to detect a high number of punctate bright fluorescent structures in the endoplasm (Fig. 3a), the incubation time had to be extended to $30 \mathrm{~min}$.

We further tried the very popular fluid-phase marker Lucifer Yellow, which has a rather dim fluorescence (5 $\mathrm{mM}^{-1} \mathrm{~cm}^{-1}$ brightness, calculated with data from Stewart (1981)), and a slightly smaller Stokes radius than AF488HA (Heyman and Burt 2008). After pulsing for 10 min with $10 \mathrm{mM}$ Lucifer Yellow, abundant fluorescent particles were visible in the endoplasm of Chara cells (Fig. 3b). Lower concentrations gave unsatisfactory staining, most probably because of the lower molecular brightness of the dye. 

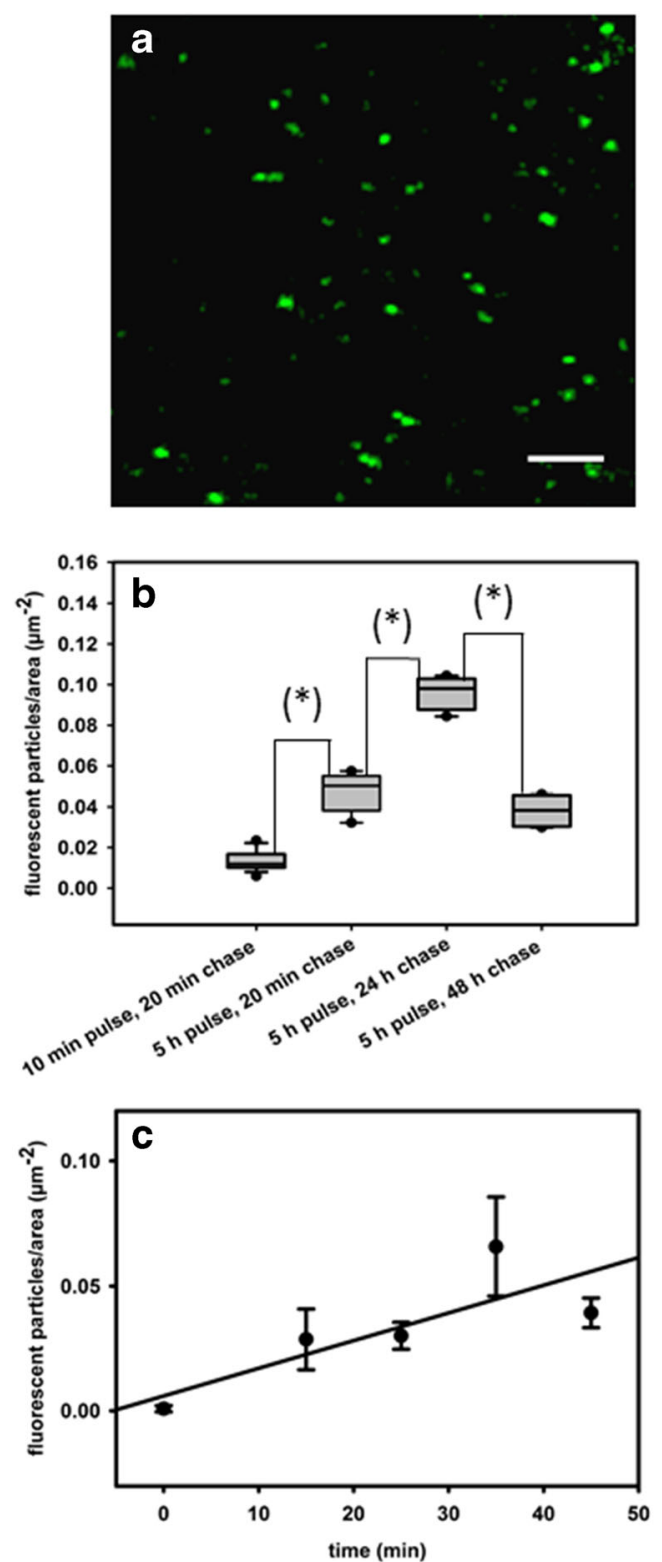

Fig. 2 Uptake of the fluid phase marker AF488HA in Chara cells shows linear time dependence and is inhibited by cold. a After $10 \mathrm{~min}$ incubation with $2 \mathrm{mM} \mathrm{AF} 488 \mathrm{HA}$ and $20 \mathrm{~min}$ chase, green fluorescent punctate structures are visible in the cytoplasm. Bar is $5 \mu \mathrm{m}$. b Box plot of the number of fluorescent particles per area in relation to different pulsing and chasing times, using a dye concentration of $2 \mathrm{mM}$. The number of AF488HA-positive structures clearly increased after longer incubation times ( $5 \mathrm{~h}$ versus $10 \mathrm{~min}$ ) and decreased down to initial levels after 48 $\mathrm{h}$. The asterisks indicate significant differences between the data groups connected by lines (t-test, $\mathrm{P}<0.01)$. c Representative time-course plot of AF488HA uptake. Chara cells $(\mathrm{n}=6)$ were pulsed for 45 min with $2 \mathrm{mM}$ $\mathrm{AF} 488 \mathrm{HA}$ at $4^{\circ} \mathrm{C}$, and then incubated for different time periods in dyefree medium at room temperature. At time $t=0$ no particulate staining could be detected in the streaming cytoplasm, indicating the lack of internalization at $4^{\circ} \mathrm{C}$. At room temperature, the fluid phase internalization increased linearly with time

No toxic effects could be observed for the fluorescent markers tested at these concentrations. During the course of the experiments, all cells displayed normal cytoplasmic streaming, and the labeled cells had a survival rate of $100 \%$.

\section{Tracing the spatio-temporal pathway of internalized AF488HA}

During initial steps of endocytosis, primary endocytic vesicles internalize membrane and external fluid-phase cargo. Endocytosed material is then progressively delivered to early endosomes through several membrane fusion and content mixing steps, which occur in a well-regulated spatio-temporal sequence. These events are well documented in animal cells (Rink et al. 2005), but comparatively little is known to date about these processes in plant cells.

In order to get insight into endosome progression we performed sequential pulse-staining with different fluorescent dyes. Chara cells were first incubated with $2 \mathrm{mM}$ AF568HA for $30 \mathrm{~min}$, which allowed extensive distribution of the fluid-phase marker to compartments of the endocytic pathway. After a 10 min washing step, the cells were incubated for $30 \mathrm{~min}$ with $10 \mathrm{mM}$ Lucifer Yellow, and after another $10 \mathrm{~min}$ wash in dye free medium the cells were examined with the confocal microscope. As illustrated in Fig. 3d, very few endosomes were stained by both markers, resulting in a poor co-localization of the fluorescent signals (Fig. 3e). This indicates that the two dyes were entrapped in distinct organelles, and accordingly, no significant fusion with content mixing occurred between compartments recently labeled by Lucifer Yellow, and earlier endocytic structures stained by AH568HA. Thus, the emerging picture is that fluid phase cargos loaded consecutively at a time interval of ca. $80 \mathrm{~min}$ did not "meet" within the same vesicular structures, but were spatially sorted into different late compartments, with diminished fusion competence. These results are similar to findings reported by (Salzman and Maxfield 1988, 1989), who showed that in mammalian cells, fusion occurred mainly between primary endocytic vesicles formed at 5 to 15 min interval, and at the early endosome, whereas fusion competence decayed for late endosomes, situated downstream on the endocytic pathway.

We further performed immunofluorescence microscopy and used antibodies to label early (TGN) and late compartments, i. e. MVBs and prevacuolar compartments (PVCs). In order to prove if after $30 \mathrm{~min}$ exposure to $2 \mathrm{mM} \mathrm{AH} 488 \mathrm{HA}$ the marker is present in early endocytic compartments, we immuno-labeled the cells with OsSCAMP, an antibody used as a bona fide marker for TGN (Lam et al. 2007). As illustrated in Fig. 4a-c, the fluorescent hydrazide, which is readily fixable by glutaraldehyde, stained the lumen of numerous endosomes, some of them bearing epitopes recognized by anti-OsSCAMP. However, the co-localization of the two markers is low (Fig. 4d), indicating that after $30 \mathrm{~min}$ the internalized fluid-phase can only occasionally be found in early 

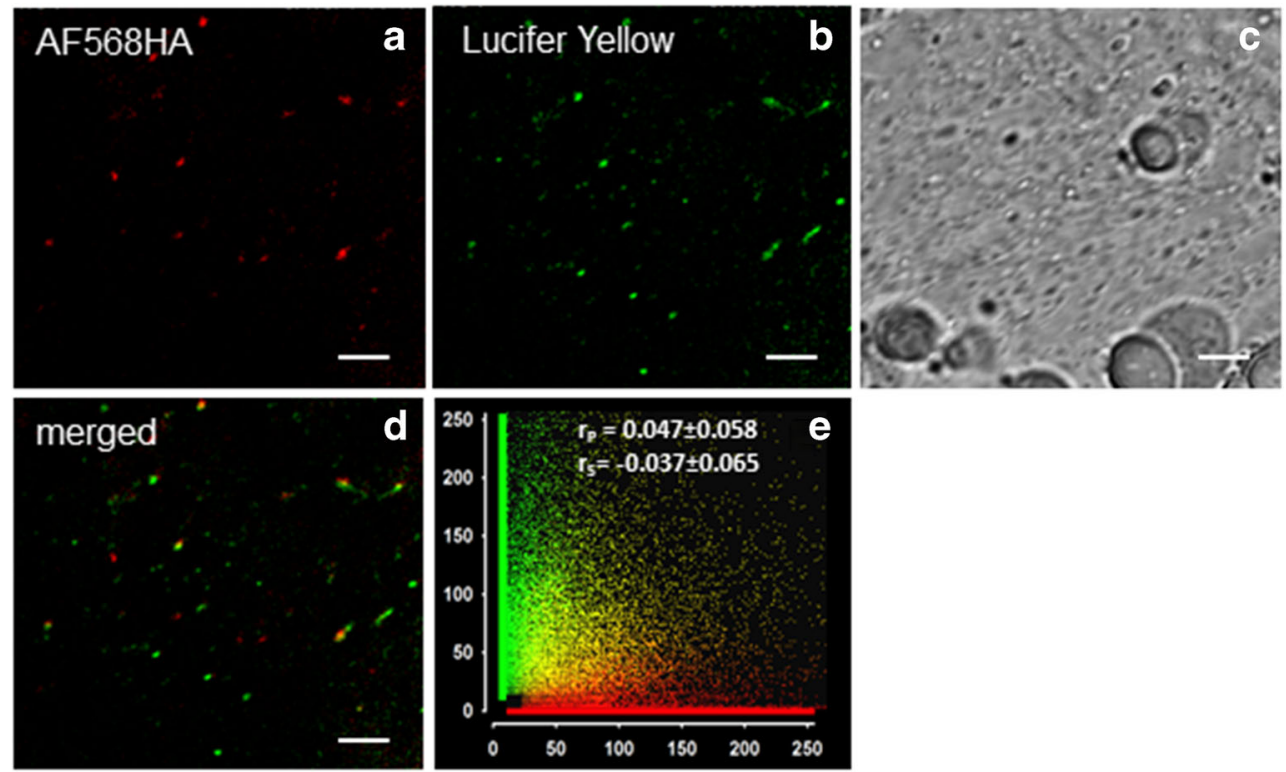

Fig. 3 Distribution of sequentially internalized fluid phase markers. Chara cells were pulse-labeled for 30 min with $2 \mathrm{mM}$ AF568HA, washed in dye-free medium and then incubated for $30 \mathrm{~min}$ with $10 \mathrm{mM}$ Lucifer Yellow. Images were taken after $10 \mathrm{~min}$ wash in dye-free medium. The punctate structures indicate endocytic compartments stained with: (a) AF568HA, (b) Lucifer Yellow; (c) corresponding bright field image; (d) merged image of (a) and (b). e Scatterplot derived from the co-

localization analysis of AF568HA positive and Lucifer Yellow stained particles. The quantification was performed using the PSC plug-in of ImageJ (French et al. 2008) on 627 individual fluorescent spots manually masked from time-lapse recordings taken from 3 different cells. Pearson's $\left(r_{p}\right)$ and Spearman's correlation $\left(r_{s}\right)$ coefficients are given as means \pm SD. Bars in (a-d) are $5 \mu \mathrm{m}$

endocytic compartments (TGNs). It is thus probable that, during this time interval, the fluid-phase cargo distributed predominantly to organelles situated downstream the TGN, or on a TGN subpopulation that lacked the SCAMP epitopes.

ARA7 is a member of the RAB5 GTPases group of higher plants, which localizes to late endosomes (Lee et al. 2004; Ueda et al. 2004), and an ARA7 homolog, CaARA7 was identified in Chara australis (Hoepflinger et al. 2015). Here we used an affinity-purified antibody against CaARA7 in order to test if external fluid-phase cargo can be identified in late compartments after $30 \mathrm{~min}$ incubation with the dye. Figure 4e$\mathrm{h}$ illustrates that the endocytic compartments labeled by the FPE marker and the CaARA7-positive endosomes match to a higher degree, in support of the hypothesis that after $30 \mathrm{~min}$ incubation much of the dye reached late endocytic compartments.

In a further attempt to identify the membrane-bound compartments that enclosed internalized fluid-phase marker, we used the acidotropic dye Lysotracker Red. After a $10 \mathrm{~min}$ pulse with $2 \mathrm{mM}$ AF488HA, the cells were incubated for $30 \mathrm{~min}$ in $5 \mu \mathrm{M}$ Lysotracker Red. Confocal imaging of the cells revealed poor co-localization of the two fluorescent signals (Fig. 4i-1), suggesting that after at least $40 \mathrm{~min}$ (pulse time included) the fluid-phase marker can be identified mainly in neutral, and much less in acidic endosomes. In plant cells, unlike in animal cells, $\mathrm{H}^{+}$-ATPase activity was detected in the early endosomes which consequently have an acidic lumen, but is lacking in the late endocytic compartments
(MVBs/PVC) which have an almost neutral internal $\mathrm{pH}$ (Dettmer et al. 2006; Martiniere et al. 2013; Robinson and Pimpl 2014; Luo et al. 2015; Robinson and Neuhaus 2016). This finding, therefore, reinforces the idea that after ca. 30 min, the internalized fluid-phase marker passed from early to late endocytic compartments.

\section{Fluid-phase - and membrane endocytosis markers co- localize following concomitant pulse incubation}

As an additional proof of the endocytic nature of fluid-phase uptake in Chara we used the styryl fluorescent membrane marker FM4-64 in conjunction with the FPE marker AF488HA. Previous work has shown that styryl dyes stained the plasma membrane of Chara internodal cells, including convoluted domains (charasomes) if present (Klima and Foissner 2008). Few minutes after addition, these dyes were found to label punctate organelles in the stationary cortex and in the streaming endoplasm. In the present work, we pulsed the cells concomitantly with $2 \mathrm{mM}$ AH488HA (green fluorescence) and $10 \mu \mathrm{M}$ FM4-64 (red fluorescence) on ice and chased the two markers after $40 \mathrm{~min}$ at room temperature. As can be seen in Fig. 5a and b, many mobile, punctate fluorescently labeled structures can be identified in the endoplasm, and the overlay in Fig. $5 \mathrm{c}$ validates the endocytic nature of the fluid-phase uptake. Co-localization analysis (French et al. 2008) revealed good co-localization of the fluorescent signals (Pearson's $r_{s}=0.566 \pm 0.106$, Spearman's $r_{p}=0.524 \pm 0.121$, 


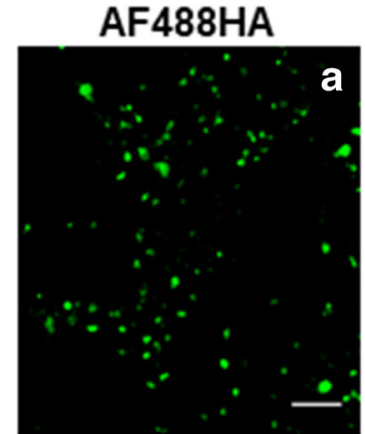

AF488HA

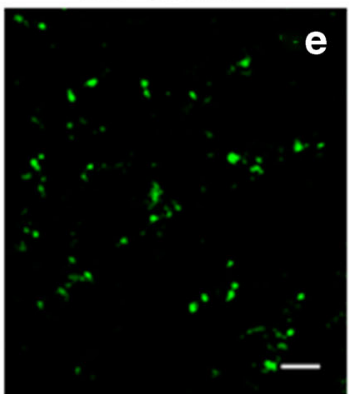

AF488HA
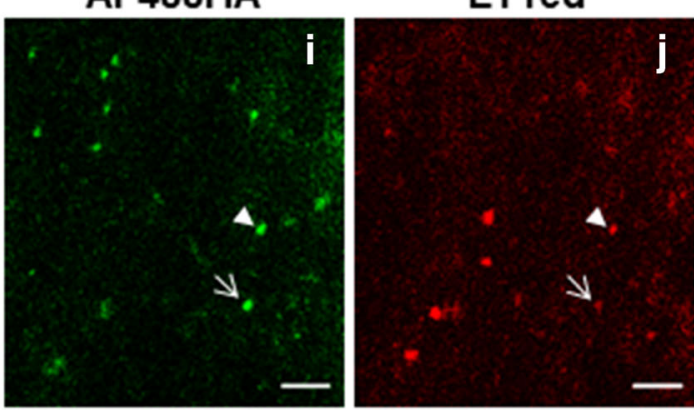

Fig. 4 AF488HA distributes to early and late compartments of the endocytic pathway. a-d Immunofluorescence of AF488HA stained cells (a) with anti-OsSCAMP, a TGN-specific antibody (b). Only few organelles are stained by both markers, as shown in the merged image (c) and in the scatterplot (d). e-h Immunofluorescence of AF488HA stained cells (e) with anti-CaARA7 (f), which specifically recognizes MVBs. Merged image (g) and scatterplot (h) reveal a higher degree of co-localization. i-l Organelles stained by fluid phase marker AF488HA (i) are rarely stained by the acidotropic dye Lysotracker Red (j-l). The arrowheads in (i-k) point to an acidic compartment intensely stained by the fluid phase marker, whereas the arrows identify a less acidic endosome (weak fluorescence

Fig. 5d). The values of the correlation coefficients generally reflect the relationship between the intensities of the fluorophores not only their distribution to the same compartments. Another possibility to describe the distribution pattern of two fluorescent markers is to quantify the frequency of the co-occurrence in the same endocytic compartments, irrespective of the signal intensity. Measurements using the Cell Counter plugin of ImageJ revealed that $94.2 \%$ of the green fluorescent particles displayed also red fluorescence (1000 particles from 3 cells were analyzed).
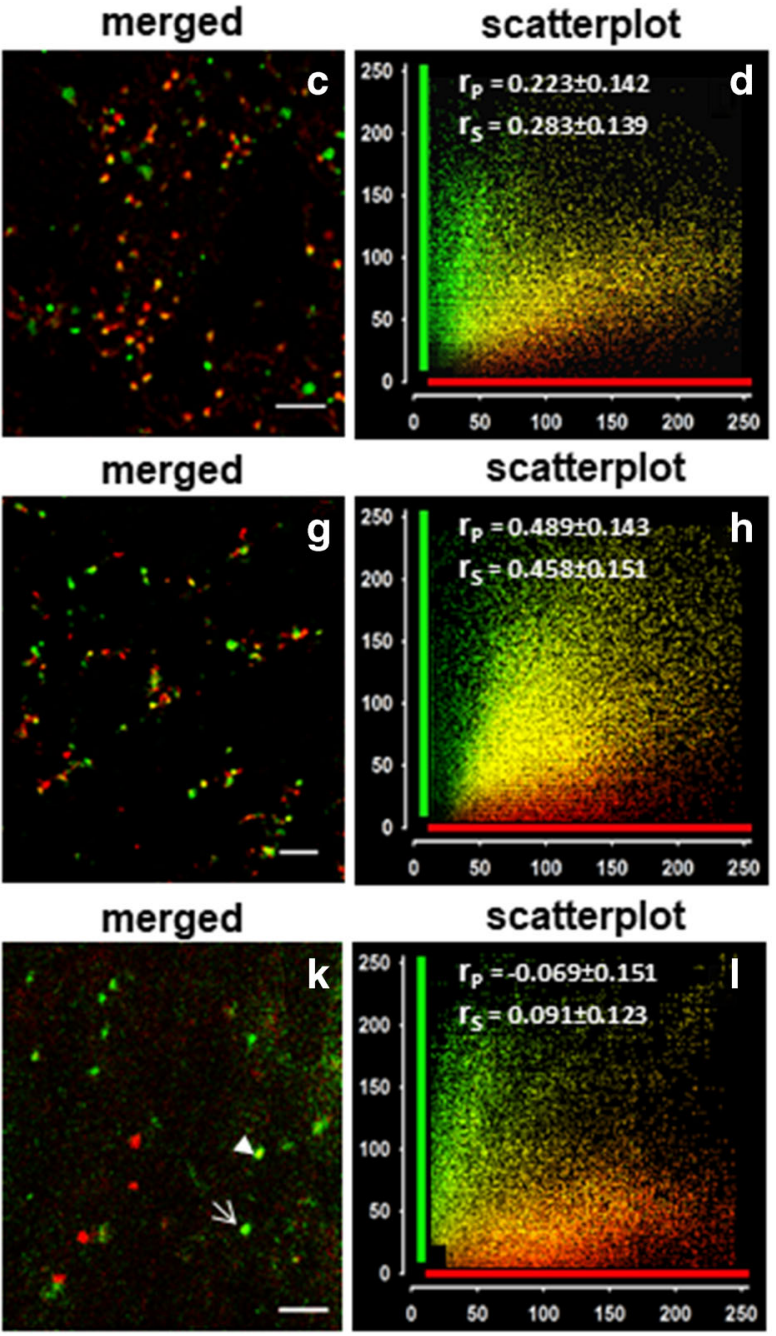

in the red channel) that is strongly stained by AF488HA. Cells were incubated with $2 \mathrm{mM}$ AF488HA for $30 \mathrm{~min}$ prior to fixation for immunofluorescence (a and e). For the comparison with the acidotropic dye cells were pulse-labeled for 10 min with AF488HA (i) and then incubated with $5 \mu \mathrm{M}$ Lysotracker red for $30 \mathrm{~min}$. Consequently, AF488HA was chased in the endocytic compartments after times comparable to the immunostaining experiments. For the co-localization analysis the PSC plugin of ImageJ was used; 230 to 526 green fluorescent structures from 3 cells were manually masked and the resulting cumulative scatterplots together with the Pearson's $\left(\mathrm{r}_{\mathrm{P}}\right)$ and Spearman's $\left(\mathrm{r}_{\mathrm{S}}\right)$ correlation coefficients are shown in (d), (h) and (l). Bars are $5 \mu \mathrm{m}$

When we used short pulse incubations for the parallel uptake of AF488HA and FM-dyes at room temperature, and the markers were chased after 20 to $30 \mathrm{~min}$, we found that: (a) the number of endocytic structures stained by the membrane styryl dye exceeded considerably the number of AH488HApositive ones, and (b) the membrane of more than $40 \%$ of the AF488HA-enclosing endosomes was not stained by FM4-64 (Figs. 5e-f). The lack of full co-localization between FM dyes and other endocytic markers is not restricted to Chara cells, but is a frequently reported phenomenon (Chow et al. 2008; Etxeberria et al. 2009; Gall et al. 2010; Bandmann et al. 2012; 


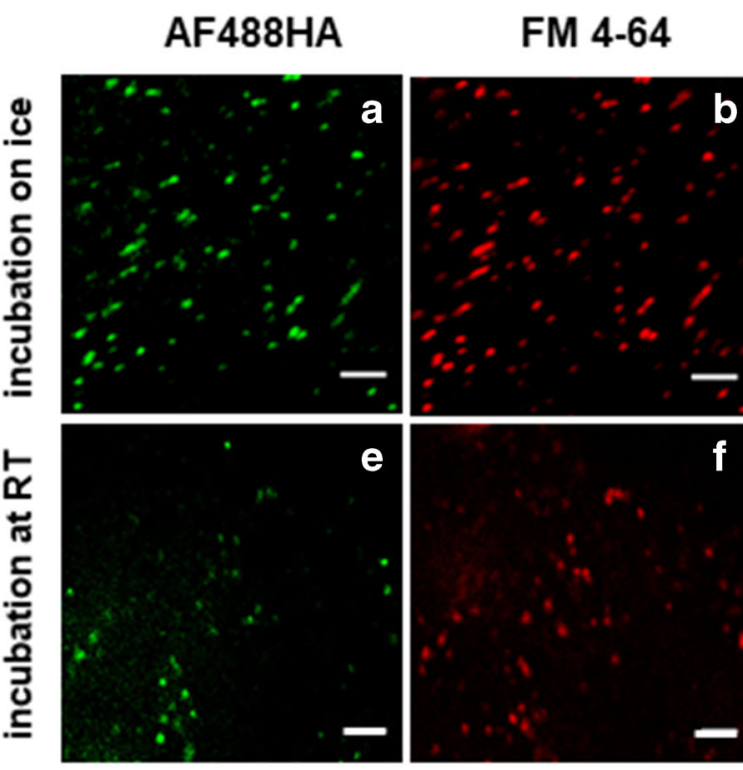

Fig. 5 Co-localization of fluorescent fluid-phase and membrane markers after simultaneous pulse-staining. Chara cells were simultaneously incubated with $2 \mathrm{mM} \mathrm{AF} 488 \mathrm{HA}$ and $10 \mu \mathrm{M}$ styryl dye FM4-64 for $45 \mathrm{~min}$ on ice (a-d) or $10 \mathrm{~min}$ at room temperature (e-f) and chased after 20 to 40 min. The scatterplots show that the fluorescent signals in the endocytic

Li et al. 2012; Hoepflinger et al. 2013; Palocci et al. 2017). Although we cannot exclude selective cargo sorting, we hypothesize that the lack of full co-localization of fluid-phase and endocytic membrane markers at room temperature reflects a staining and/or detection problem probably due to different retention times within the cell wall and hence different arrival of markers at the plasma membrane. This finding also points to the limits of using these endocytosis markers and the need for careful experiments.

\section{The compartments that internalize AF488HA are wortmannin- and BFA-sensitive}

Wortmannin is a fungal metabolite that inhibits phosphatidylinositol-3 (PI3) and phosphatidylinositol-4 (PI4) kinases and is widely used as an inhibitor of endocytosis. In Chara cells, we found that wortmannin did not inhibit endocytosis up to a concentration of $50 \mu \mathrm{M}$, but induced the formation of "mixed compartments" consisting of MVBs and membranous material probably derived from TGN, as well as enlargement of MVBs by homotypic fusions, especially in cells recovering from wortmannin treatment (Foissner et al. 2016). In the present study, we examined the staining pattern of wortmannin-induced compartments using fluidphase and membrane markers. For this, Chara internodal cells were simultaneously pulse-labeled with $2 \mathrm{mM} \mathrm{AF} 488 \mathrm{HA}$ and $10 \mu \mathrm{M}$ FM4-64 for $10 \mathrm{~min}$ at room temperature, and then treated with $25 \mu \mathrm{M}$ wortmannin for $30 \mathrm{~min}$. Immediate examination of the cells showed largely the same staining patterns as controls, but inspection after $2 \mathrm{~h}$ revealed the appearance of merged
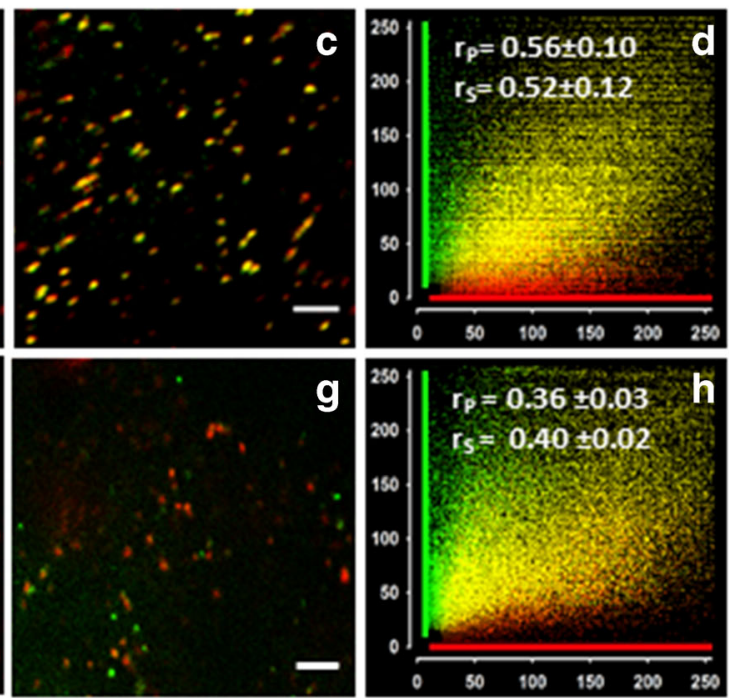

compartments largely co-localize, proving the endocytic nature of fluidphase uptake. Bars are $5 \mu \mathrm{m}$. For scatterplot (d) 1000 green fluorescent structures from 3 cells and for scatterplot (h) 1473 structures from 14 cells were analyzed with the PSC plugin of ImageJ. Pearson's $\left(r_{P}\right)$ and Spearman's $\left(r_{S}\right)$ correlation coefficients are indicated

large membrane-bound compartments that were labeled by both fluid-phase and membrane markers (Fig. 6a-c; yellow arrows). Occasionally, larger endosomes with a size of about $1.5 \mu \mathrm{m}$ were noticed, that presented only one type of fluorescence (white thick arrows in Fig. 6a and b), and probably originated from homotypic fusions of single-stained compartments. The fine structure of control cells and the enlarged wortmannin compartments is presented in Fig. 7. It proves that they are of MVB origin and remnants of the TGN. The presence of both fluorescent markers in these large wortmannin compartments is consistent with the immunofluorescence data and suggests that after longer chasing times the membrane and fluid phase cargo reached late endocytic compartments.

We next investigated the effect of the fungal toxin BFA, a popular inhibitor of protein trafficking, on constitutive endocytosis in Chara. For in vivo staining, Chara cells were simultaneously pulse-labeled with $2 \mathrm{mM} \mathrm{AF} 488 \mathrm{HA}$ and $10 \mu \mathrm{M}$ FM4-64 for $10 \mathrm{~min}$ at room temperature, then treated with $200 \mu \mathrm{M}$ BFA for $30 \mathrm{~min}$. In BFA-treated cells, very large organelle-aggregates were frequently detected in the flowing cytoplasm. Their endocytic origin was demonstrated by the presence of both fluid-phase and membrane markers AF488HA and FM4-64, respectively (Fig. 6d). As shown in the scatter plot of Fig. S1, the fluorescent signals in the green and red channel revealed a high degree of co-localization in BFA-compartments. Enlarged single-stained compartments were not detected. After $3 \mathrm{~h}$ incubation in dye-free medium the cells recovered and regained the fluorescent punctate staining of the cytoplasm, demonstrating that the BFA effect is 


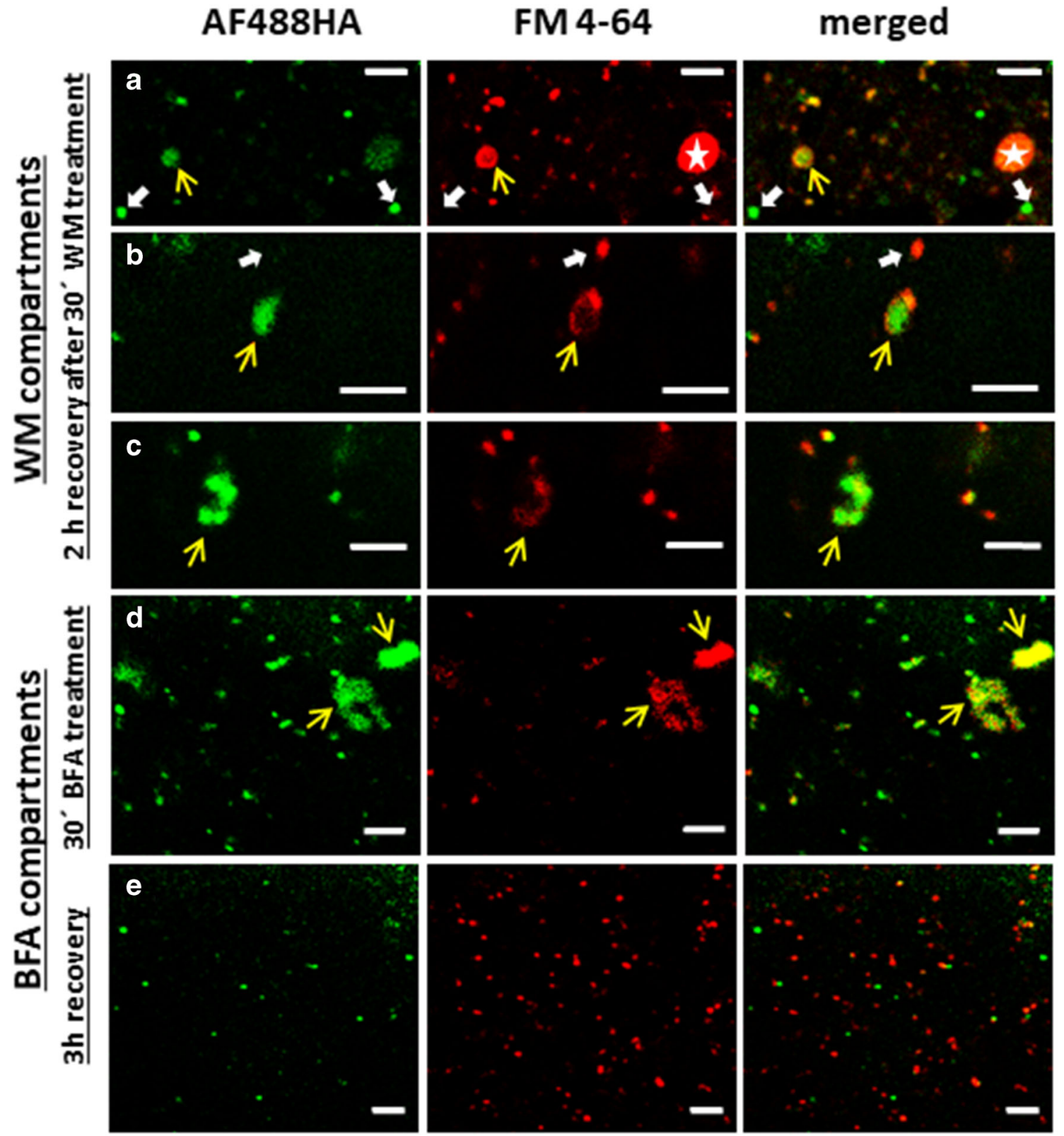

Fig. 6 Localization of plasma membrane- and fluid phase markers in wortmannin- and BFA-treated Chara cells. Cells were simultaneously pulse-labeled with $2 \mathrm{mM} \mathrm{AF} 488 \mathrm{HA}$ and $10 \mu \mathrm{M}$ FM4-64 for $10 \mathrm{~min}$ before adding the inhibitors. a-c Three examples for endoplasmic organelles in cells "recovering" for $2 \mathrm{~h}$ from 30 min treatment with $25 \mu \mathrm{M}$ wortmannin (WM). Thin yellow arrows indicate compartments labeled by both dyes and thick white arrows indicate single-stained compartments. The white star in (a) marks a red fluorescent chloroplast. $\mathbf{d}$ and $\mathbf{e}$ Endoplasmic organelles in cells treated with $200 \mu \mathrm{M}$ BFA for $30 \mathrm{~min}$ (d; arrows indicate typical organelle-aggregates known as BFA-compartments) and in cells recovering for $3 \mathrm{~h}$ from BFA-treatment (e). Bars $=5$ $\mu \mathrm{m}$

observations together with the fluorescence microscopy data suggest that during the $10 \mathrm{~min}$ pulse the dyes stained extensively the early endocytic compartments, and the rapid action of BFA concentrated the markers in TGN-containing BFA-compartments. Notably, qualitative inspection of the punctate structures in the red and green fluorescence channel revealed that the colocalization of two endocytosis markers diminished after the recovery phase (not shown). 
Fig. 7 Effect of wortmannin and BFA on the fine structure of internodal cells. a Golgi body $(\mathrm{G})$, TGN and MVB (inset) in the endoplasm of a control cell. $\mathrm{M}=$ mitochondrion, $\mathrm{C}=$ chloroplast. b Formation of aggregates consisting of TGN-tubules (arrow) and MVBs (asterisks) in a cell treated with $50 \mu \mathrm{M}$ wortmannin for $2 \mathrm{~h}$. c Huge MVBs (asterisks) in a cell recovering from wortmannin treatment $(25 \mu \mathrm{M}$ wortmannin for $30 \mathrm{~min}$, $2 \mathrm{~h}$ recovery in artificial fresh water). d Agglomeration of Golgi bodies and TGN following 30 min treatment with $200 \mu \mathrm{M}$ BFA. Bars are $1 \mu \mathrm{m}$
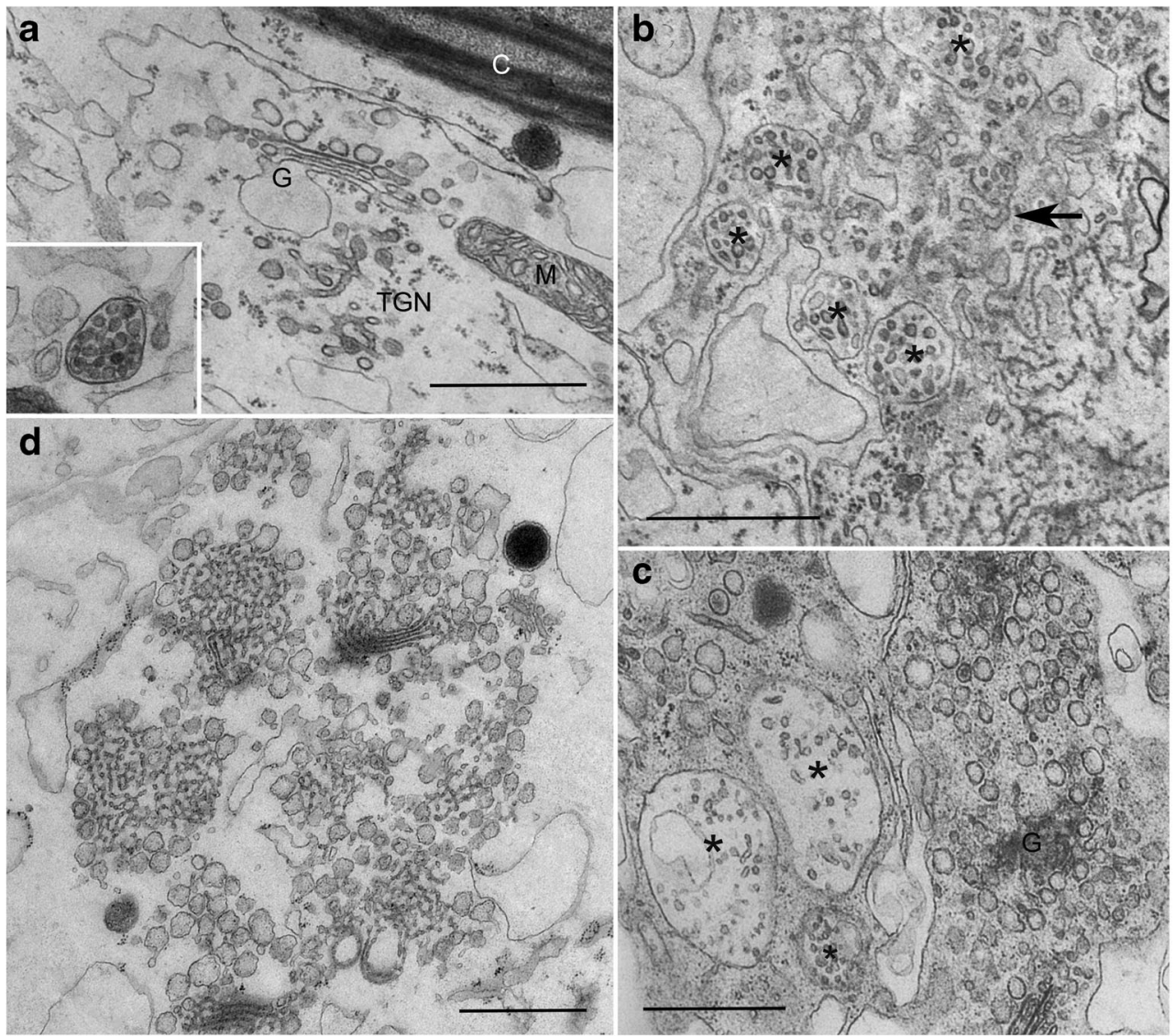

\section{Uptake of AF488HA is not disturbed by the actin depolymerizing agent cytochalasin $D$ but is inhibited by ikarugamycin and methyl-ß-cyclodextrin}

Next, we investigated the effect of several inhibitors on the internalization of AH488HA in order to find out whether fluid phase endocytosis in Chara cells depends on actin and clathrin.

In the inner cortex cells of maize root apices, the uptake of Lucifer Yellow was found to be dependent on Factin (Baluska et al. 2004). In order to investigate if actin is similarly involved in the fluid-phase uptake and internalization in Chara, we used cytochalasin D which reversibly inhibits actin-based motility and transiently reorganizes the delicate cortical actin filament meshwork in characean algae into short, thick rods (Foissner and Wasteneys 2000; Foissner and Wasteneys 2007). Internodal cells were treated with 10,50 or $100 \mu \mathrm{M}$ cytochalasin D for $30 \mathrm{~min}$, and then stained for $10 \mathrm{~min}$ with $2 \mathrm{mM}$ AF488HA containing the corresponding inhibitor concentrations. Even at $100 \mu \mathrm{M}$, which completely arrested cytoplasmic streaming, we were able to detect numerous AF488HA-stained particulate structures, which performed wiggling, probably saltatory movements in the stagnant endoplasm (Fig. S2, Video S3).
We further used the pharmacological tools ikarugamycin and methyl-3-cyclodextrin, known to inhibit the formation and the trafficking of endocytic vesicles. Ikarugamycin is an antibiotic agent considered to specifically inhibit clathrin-dependent endocytosis in animal and plant cells (Hasumi et al. 1992; Luo et al. 2001; Moscatelli et al. 2007; Onelli et al. 2008; Bandmann et al. 2012; Elkin et al. 2016). Methyl- $\beta$-cyclodextrin is a sterolcomplexing agent that disrupts cholesterol-rich membrane domains and was shown to interfere with sterol-dependent endocytic pathways in plant cells (Rodal et al. 1999; Grebe et al. 2003; Boutte and Grebe 2009). We recently reported that in Chara internodal cells, ikarugamycin did not inhibit clathrincoat formation, but affected the release of coated vesicles from the plasma membrane at sub-micromolar concentrations. At concentrations of at least $100 \mu \mathrm{M}$, ikarugamycin significantly inhibited the constitutive internalization of FM dyes (Hoepflinger et al. 2017). We also showed that $20 \mathrm{mM}$ methyl-ß-cyclodextrin markedly repressed the uptake of a fluorescent membrane marker (Hoepflinger et al. 2017). In the present work, we found a similar effect of ikarugamycin and methyl- $\beta$-cyclodextrin on the uptake of the fluid-phase marker AF488HA. Both inhibitors $(100 \mu \mathrm{M}$ ikarugamycin or $20 \mathrm{mM}$ methyl- $\beta$-cyclodextrin) significantly reduced the relative number of 

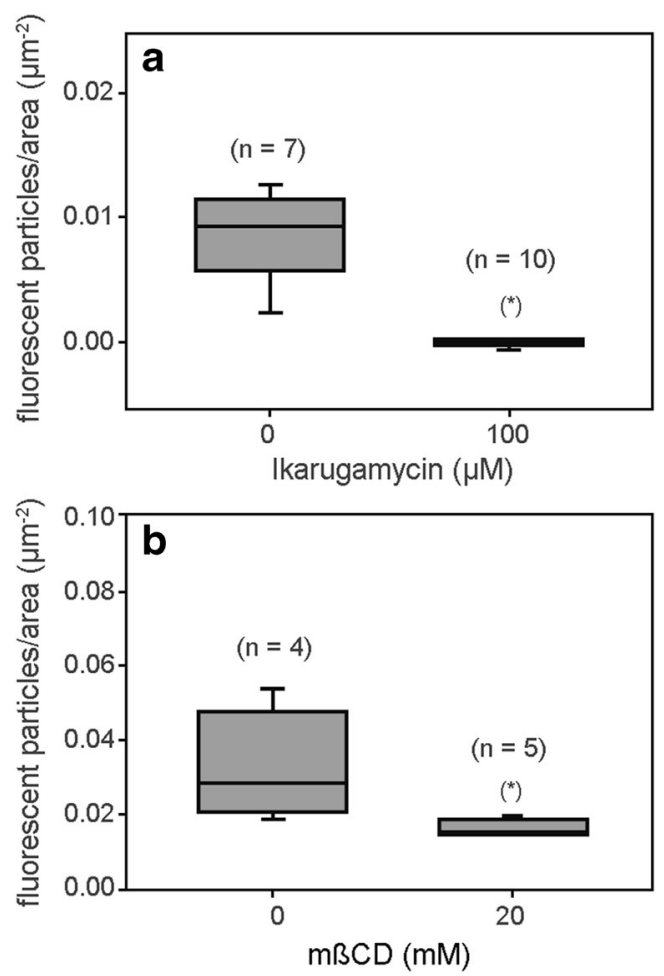

Fig. 8 Constitutive FPE in Chara is sensitive towards ikarugamycin, an inhibitor of clathrin-dependent endocytosis, and methyl- $\beta$-cyclodextrin, an inhibitor of sterol-dependent endocytosis. Internodal cells were incubated for $30 \mathrm{~min}$ with the respective inhibitors or mock- treated with artificial fresh water with appropriate additions of DMSO at room temperature. The cells were subsequently pulse-stained for $10 \mathrm{~min}$ with $2 \mathrm{mM}$ AF488HA, washed for $10 \mathrm{~min}$ in artificial fresh water and then examined under the confocal microscope. a Ikarugamycin significantly inhibited fluid phase uptake at a concentration of $100 \mu \mathrm{M}(\mathrm{P}<0.01)$. b $20 \mathrm{mM}$ methyl- $\beta$-cyclodextrin $(\mathrm{m} ß \mathrm{CD})$ also significantly reduced the number of particulate fluorescent structures in the cytoplasm $(\mathrm{P}=$ 0.026). The Mann-Whitney rank sum test was applied for the comparison between control and treated groups and one-tailed $\mathrm{P}$ values were determined. The numbers in brackets indicate the number of cells used in the experiments and the asterisks mark significant differences between treated and control cells

fluorescently labeled compartments in the endoplasm as shown in Fig. $8 \mathrm{a}$ and $\mathrm{b}$.

\section{Fluid-phase markers accumulate in compartments involved in wound healing}

In Chara internodal cells, plasma membrane wounding can be achieved by mechanical injury, by local irradiation of the cell with intense UV or blue light. We have previously shown that plasma membrane repair following local injury of internodal cells involves not only exocytosis of secretory vesicles, but also deposition of putative recycling endosomes, probably derived from the TGN (Klima and Foissner 2008; Foissner and Wasteneys 2012). We now investigated the involvement of fluid-phase containing organelles in the process of membrane repair and wound healing. In order to extensively label endocytic compartments far downstream the early endosome (e.g. putative recycling endosomes), the cells were incubated with $2 \mathrm{mM} \mathrm{AH} 488 \mathrm{HA}$ for $5 \mathrm{~h}$. They were then pulsed for 10 min with $10 \mu \mathrm{M}$ FM4-64 and transferred into dye-free medium. Local injury was performed with the $488 \mathrm{~nm}$ line of the Argon laser operated at $100 \%$ intensity for $1 \mathrm{~min}$, and using a $63 \mathrm{x}$ water immersion objective. Within seconds, an impressive accumulation of AF488HA stained particles was observed at the wounded area. They docked to the injured site (Video S4), and eventually delivered their content to the periplasmic space (Fig. 9a and b, Video S4). The presence of the fluorescent membrane marker within the secreted material (Fig. 9c and d) indicated that also FM4-64-positive endosomes gathered at the wound site, obviously participating in the membrane repair and wound-healing process, as formerly described (Klima and Foissner 2011). Figure 9b-e shows part of a freshly injured cell that was stained $2 \mathrm{~d}$ prior to imaging. Interestingly, long-lived compartments bearing AH488HA or FM4-64 still contributed in wound repair. The dynamics of the stained particles near the injured site in Video S4 strongly suggests that the fluorescence of the wound area is not due dye leakage from the external space but to the deposition of labeled organelles.

\section{Discussion}

\section{Fluid-phase markers are taken up by clathrin- mediated endocytosis in Chara branchlet internodal cells}

We have previously studied constitutive endocytosis in Chara internodal cells with fluorescent styryl dyes like FM1-43 and FM4-64, which are widely used plasma membrane markers (Klima and Foissner 2008). In the present study, we investigated constitutive endocytic pathways in more detail. We were interested in the spatio-temporal dynamics of endocytosis, with a special focus on the uptake of external fluid, which is commonly assumed to occur with all types of endocytic processes. Fluid phase uptake was extensively studied in heterotrophic cells, and it was reported to follow a clathrinindependent endocytic pathway (Etxeberria et al. 2009, 2012). We wondered if in Chara, an autotrophic alga, a similar mechanism takes place. For this purpose, we inquired the usability of fluorescent hydrazides as membrane-impermeable, fluid-phase markers in Chara internodal branchlet cells, and found that all tested markers were taken up, and could be detected in mobile cytoplasmic organelles. The colocalization with the membrane dye FM4-64 provided proof for the endocytic nature of the internalization process. The uptake was arrested by cold treatment, by ikarugamycin, an inhibitor of clathrin dependent endocytosis, and by methyl- $\beta$ cyclodextrin, which interferes with the sterol composition of 

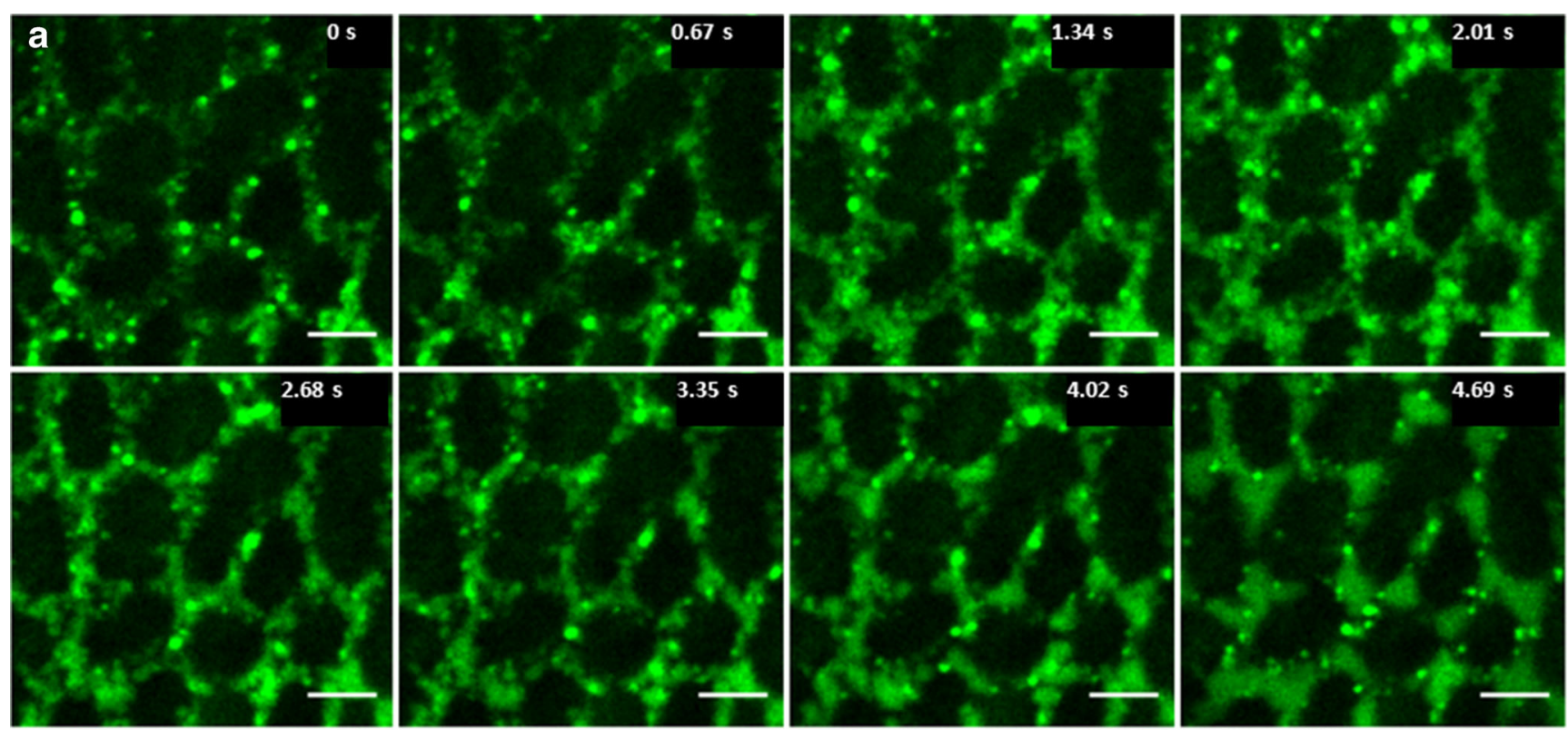
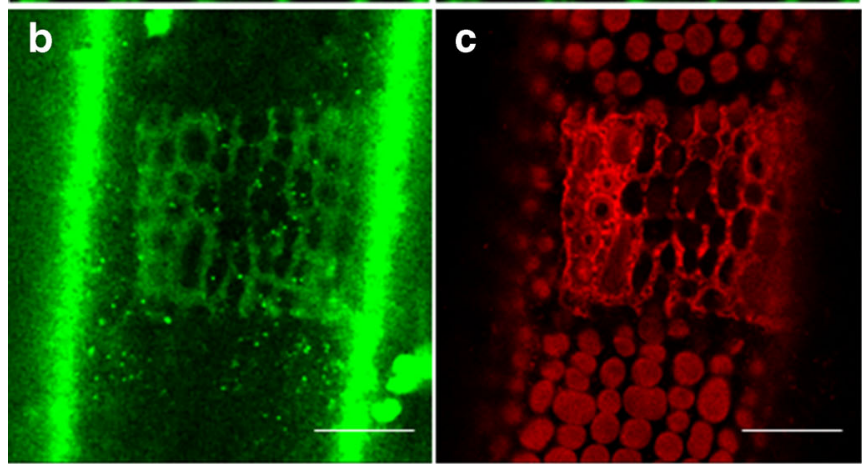

Fig. 9 Plasma membrane repair after laser injury involves participation of compartments stained by fluid phase markers and plasma membrane dyes. Chara cells were first stained with $2 \mathrm{mM} \mathrm{AF} 488 \mathrm{HA}$ for $5 \mathrm{~h}$, then pulsed with $10 \mu \mathrm{M}$ FM4-64 for $10 \mathrm{~min}$, and finally washed and suspended in dye-free artificial fresh water for confocal microscopy. Cells were injured by irradiating a region of $41 \times 41 \mu \mathrm{m}$ (the focal plane was slightly above the bleached and detaching chloroplasts) with full power of the $488 \mathrm{~nm}$ line of the Ar laser operated at $1.2 \mathrm{~mW}$. a Sequential images from a $4.69 \mathrm{~s}$ long time series, illustrating the ongoing accumulation of vesicles loaded with fluid phase marker at the

the plasma membrane. We have previously shown that inhibition by methyl- $\beta$-cyclodextrin is not due to inhibition of a clathrin-independent pathway but rather reflects the dependence of clathrin-based endocytosis on a specific set of sterols (Hoepflinger et al. 2017). In the present study, we found that fluid-phase markers were internalized in the presence of cytochalasin $\mathrm{D}$, which interferes with actin organization and actomyosin-dependent motility. These findings are in line with an earlier study showing that the internalization of membrane markers is largely independent of an intact actin cytoskeleton (Klima and Foissner 2008) and consistent with a recent study showing that actin is dispensable for clathrin-mediated events at the plasma membrane of Arabidopsis root epidermal cells (Narasimhan et al. 2020).

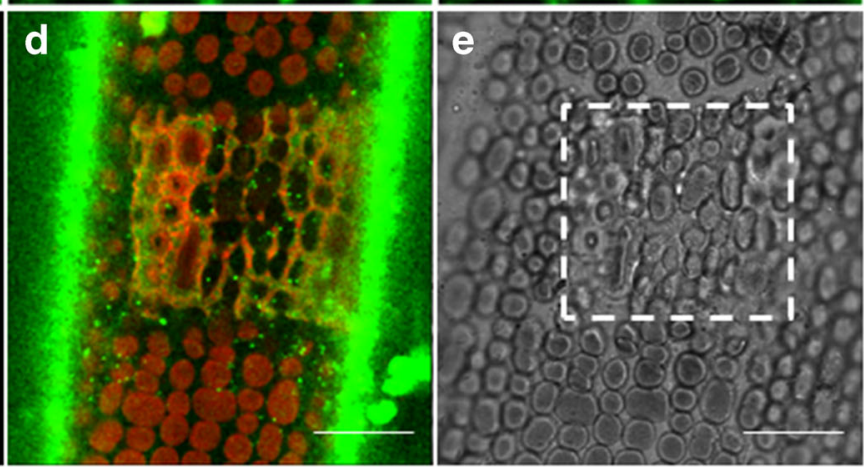

wound site. b-e Wound region of a cell, which was stained with AF488HA and FM4-64 as described above and injured after a $2 \mathrm{~d}$ wash in AFW. The deposited material contains fluid phase marker (b) and membranes stained by FM4-64 (c), both indicating the participation of long-lived endocytic compartments in wound repair. $\mathbf{d}$ is the overlay of the fluorescent signals in (b) and (c), and $\mathbf{e}$ is the corresponding brightfield image. The rectangle $\mathbf{e}$ in indicates the border of the wound. Note that the green vertical stripes in (b) represent AF488HA-residual fluorescence of the cell wall (the longitudinal axis of the cell is parallel to the vertical sides of the image). Bars are $5 \mu \mathrm{m}$ (a) and $20 \mu \mathrm{m}$ (b-e)

To sum up, our data suggest that both fluid-phase and plasma membrane are predominantly internalized by a clathrindependent and actin-independent mechanism (see also Hoepflinger et al. 2017), even though the existence of a clathrin-independent pathway cannot be fully excluded. The time-dependent distribution and accumulation of fluorescent fluid-phase marker in compartments of the endocytic pathway (TGN, MVBs/PVCs) was confirmed by immunofluorescence and by treatment of cells with wortmannin and BFA. We therefore provide here convincing evidence that FPE is constitutively operating in cells of the autotrophic giant alga Chara australis and that fluorescent Alexa hydrazides markers in $\mathrm{mM}$ concentrations are well suited to trace extracellular fluid within compartments of the endocytic pathway. Contrary to other studies, however, it was not possible to 
detect these markers in the cytoplasmic vacuoles or in the central vacuole of Chara internodal cells. We hypothesize that the concentration of the fluorescent dyes in these huge compartments was beneath the detection limit.

\section{AF488HA distributes sequentially to early and late endosomes of the endocytic pathway and reveals very long-lived compartments}

In all eukaryotic cells, the endocytic vesicles formed by plasma membrane invagination and subsequent scission build a well-orchestrated dynamic network, that undergoes spatiotemporal progression and maturation (Rink et al. 2005; Scheuring et al. 2011). In order to perform tasks of sorting, processing and recycling, these endocytic structures fuse with each other and/or with pre-existing endosomal compartments. During these events, the luminal cargo designed for degradation or recycling is retained and gradually accumulates within individual endosomes on progressing from early to late status (Rink et al. 2005).

In the present study, initial endocytic events have escaped our observation, since it was not possible to use very short chasing times required for detecting primary endocytic vesicles. On the one hand, incubation times of at least 10 min were necessary, probably because the diffusion of the negatively charged fluid-phase markers was slowed down by the repellent, negatively charged polyanionic pectins, and also sizerestricted by the narrow and tortuous pores in the cell wall. The idea that the cell wall acted as a filter barrier is supported by the observation that higher molecular weight AF568HA needed longer incubation times to produce a staining intensity similar to lower molecular weight AF488HA. On the other hand, extensive washing of the cells in dye-free medium was necessary, in order to reduce the residual staining of the cell wall. During this time period the fluorescent markers were distributed to a wide variety of compartments of endocytic origin (see Ueda et al. 2001; Bolte et al. 2004; Klima and Foissner 2008; Hoepflinger et al. 2015 and references therein).

Considering the unusually large size of Chara internodes (here up to $2 \mathrm{~cm}$ ) and the fact that cytoplasmic organelles, including endosomes are thus conveyed around long distances with the highest known velocity $\left(100 \mu \mathrm{m} \cdot \mathrm{s}^{-1}\right)$, one may ask if the dynamics of cargo transfer between endocytic compartments also shows unusual features. By using concomitant and sequential pulsing with fluid-phase-, membrane- and $\mathrm{pH}$-markers, as well as chasing at varying time intervals, we were able to stain different sub-populations of endosomes, and to reveal interesting characteristics of compartment mixing and maturation. These results, as well as our immunofluorescence data, indicate that AF488HA distributed within $10 \mathrm{~min}$ to early (TGN) and after 30 min to late endocytic compartments (MVBs). Notably, these time durations reflect the temporal dynamics of the accumulation of the internalized fluid- phase in early endosomes and of sorting to late compartments, respectively, along the endocytic pathway. This is in agreement with the idea that the TGN temporarily accumulates internalized solutes (Bandmann and Homann 2012; Etxeberria et al. 2012), and that after passing the TGN, endocytic cargo reaches late endocytic compartments (Tanchak and Fowke 1987; Dettmer et al. 2006; Onelli et al. 2008; Bottanelli et al. 2011). Further confirmation came from inhibitor experiments, which showed that fluid-phase markers accumulated in compartments induced by BFA, which consist of Golgi and TGN vesicle aggregates (e.g. Hause et al. 2006; Tse et al. 2006; Naramoto et al. 2014), as well as in wortmannin-induced compartments, which mainly form by homotypic fusion of MVBs (e. g. Jaillais et al. 2006; Tse et al. 2006; Wang et al. 2009; Takac et al. 2012; Foissner et al. 2016).

Interestingly, fluid cargo that was internalized consecutively at time intervals of more than $60 \mathrm{~min}$ did not accumulate within the same vesicular structures, nor could it be detected in the vacuole, but it was sorted into spatially distinct late compartments. In animal cells, cargo transfer from early to late endosomes follow a first-order kinetics, with a half time of 10-15 min (Salzman and Maxfield 1988, 1989; Rink et al. 2005). Toyooka et al. (2009) reported that in BY2 cells after 10 to 15 min incubation, the styryl dye FM4-64 colocalized with YFP-SCAMP positive compartments identified as TGN. Furthermore, in Arabidopsis leaves, the flagellin sensing membrane receptor FLS2 reached late endosomal compartments after 30 to $50 \mathrm{~min}$ of flagellin elicitation (Beck et al. 2012), and in root tips Ravikumar et al. (2018) found that the TGN was stained after about 8-10 min after FM4-64 application. All these time-scales are well comparable to the time scale of endosome-progression found by us in Chara in spite of huge cell size differences.

In the course of this study, we revealed the presence of stable, long-lived compartments, which retained their luminal content up to two days after pulse-staining. This finding amends the prevailing view that all endocytic compartments are transitory structures with a high turnover rate. Kang (2014) hypothesized that the plant TGN is likely to be a single-use compartment, which is replenished regularly by membrane trafficking, and Scheuring et al. (2011) suggested that the MVBs/PVCs are non-persistent compartments, that are continuously formed and ultimately consumed through fusion with the vacuole. However, it was also hypothesized that some TGN units may be relatively long-lived (Gendre et al. 2015). Our data are consistent with reports by Etxeberria et al. (2006), who found that fluorescent quantum dots internalized by fluid-phase endocytosis persisted in the cytoplasm of sycamore cultured cells for more than $18 \mathrm{~h}$. 


\section{Late endosomes are involved in plasma membrane repair}

In their native habitat, Chara internodes often experience injuries due to water currents, animals and pathogen attacks, resulting in wounding of the cell wall and local plasma membrane disruption. In order to maintain their physical and functional integrity, the cells are able to promptly repair the damage, yet the immediate source of membrane and cell wall material for wound healing are poorly characterized. Our group previously reported that at least some of the organelles deposited at the injured site in early stages of wound healing are of putative endosomal nature. In the present study we further substantiate the notion that vesicles of endocytic origin are implicated the membrane restoration process, delivering the material for membrane resealing.

For this study we used local irradiation with strong laser light to damage the plasma membrane and to induce wound healing. Local laser injury of AH488HA-labeled characean internodal cells revealed a strong involvement of organelles containing the fluorescent fluid-phase marker in the process of membrane repair. Cells that were stained for $5 \mathrm{~h}$, and then suspended in dye-free medium reacted with extensive deposition of fluid-phase marker at the wound site, delivered by numerous stably stained compartments from a pool formed well before membrane injury. These results prove an active participation of endocytic organelles in the membrane repair process in Chara, in accordance to previous findings (Klima and Foissner 2011). We assume that putative recycling endosomes and probably late endocytic compartments (MVBs) stained with AF488HA were among the repair compartments. Callose was previously found to accumulate at the wound site in Chara (Foissner and Wasteneys 2012; Klima and Foissner 2011), and Bohlenius et al. (2010) suggest that callose synthase is loaded via MVBs at papillae formed upon powdery-mildew invasion in barley (see also Gu et al. 2017).

Supplementary Information The online version contains supplementary material available at https://doi.org/10.1007/s00709-021-01627-z.

Acknowledgements The authors are grateful to Prof. Liwen Jiang, University of Hong Kong, for providing the antibody against OsSCAMP1.

Contributions A. S. designed experiments, performed in vivo imaging and statistical evaluation of data. M. H. carried out electron microscopy. All authors contributed to the writing of the manuscript.

Funding Open access funding provided by Austrian Science Fund (FWF). This study was funded by the Austrian Science Fund (FWF; project no. P 22957 and P27536 to IF).

\section{Declarations}

Conflict of interest The authors declare that they have no competing interests.
Open Access This article is licensed under a Creative Commons Attribution 4.0 International License, which permits use, sharing, adaptation, distribution and reproduction in any medium or format, as long as you give appropriate credit to the original author(s) and the source, provide a link to the Creative Commons licence, and indicate if changes were made. The images or other third party material in this article are included in the article's Creative Commons licence, unless indicated otherwise in a credit line to the material. If material is not included in the article's Creative Commons licence and your intended use is not permitted by statutory regulation or exceeds the permitted use, you will need to obtain permission directly from the copyright holder. To view a copy of this licence, visit http://creativecommons.org/licenses/by/4.0/.

\section{References}

Adlassnig W, Koller-Peroutka M, Bauer S, Koshkin E, Lendl T (2012) Lichtscheidl IK. Endocytotic uptake of nutrients in carnivorous plants Plant J 71:303-313. https://doi.org/10.1111/j.1365-313X. 2012.04997.x

Baisa GA, Mayers JR, Bednarek SY (2013) Budding and braking news about clathrin-mediated endocytosis. Curr Opin Plant Biol 16:718725. https://doi.org/10.1016/j.pbi.2013.09.005

Baluska F, Samaj J, Hlavacka A, Kendrick-Jones J, Volkmann D (2004) Actin-dependent fluid-phase endocytosis in inner cortex cells of maize root apices. J Exp Bot 55:463-473

Baluska F, Liners F, Hlavacka A, Schlicht M, Van Cutsem P, McCurdy DW, Menzel D (2005) Cell wall pectins and xyloglucans are internalized into dividing root cells and accumulate within cell plates during cytokinesis. Protoplasma 225:141-155. https://doi.org/10. 1007/s00709-005-0095-5

Bandmann V, Homann U (2012) Clathrin-independent endocytosis contributes to uptake of glucose into BY-2 protoplasts. Plant J 70:578584

Bandmann V, Muller JD, Kohler T, Homann U (2012) Uptake of fluorescent nano beads into BY2-cells involves clathrin-dependent and clathrin-independent endocytosis. FEBS Lett 586:3626-3632. https://doi.org/10.1016/j.febslet.2012.08.008

Bandmann V, Haub P, Meckel T (2014) Analysis of fluid-phase endocytosis in (intact) plant cells. Methods Mol Biol 1209:45-61. https:// doi.org/10.1007/978-1-4939-1420-3_4

Baral A, Irani NG, Fujimoto M, Nakano A, Mayor S, Mathew MK (2015) Salt-induced remodeling of spatially restricted clathrin-independent endocytic pathways in Arabidopsis root. Plant Cell 27:1297-1315. https://doi.org/10.1105/tpc. 15.00154

Beck M, Zhou J, Faulkner C, MacLean D, Robatzek S (2012) Spatiotemporal cellular dynamics of the Arabidopsis flagellin receptor reveal activation status-dependent endosomal sorting. Plant Cell 24(10):4205-4219. https://doi.org/10.1105/tpc.112.100263

Bohlenius H, Morch SM, Godfrey D, Nielsen ME, ThordalChristensen H (2010) The multivesicular body-localized GTPase ARFA1b/1c is important for callose deposition and ROR2 syntaxin-dependent preinvasive basal defense in barley. Plant Cell 22:3831-3844

Bolte S, Talbot C, Boutte Y, Catrice O, Read ND, Satiat-Jeunemaitre B (2004) FM-dyes as experimental probes for dissecting vesicle trafficking in living plant cells. J Microsc 214:159-173. https://doi.org/ 10.1111/j.0022-2720.2004.01348.x

Bottanelli F, Foresti O, Hanton S, Denecke J (2011) Vacuolar transport in tobacco leaf epidermis cells involves a single route for soluble cargo and multiple routes for membrane cargo. Plant Cell 23:3007-3025

Boutte Y, Grebe M (2009) Cellular processes relying on sterol function in plants. Curr Opin Plant Biol 12:705-713. https://doi.org/10.1016/j. pbi.2009.09.013 
Chaparro-Garcia A, Schwizer S, Sklenar J, Yoshida K, Petre B, Bos JIB, Schornack S, Jones AME, Bozkurt TO, Kamoun S (2015) Phytophthora infestans RXLR-WY effector AVR3a associates with dynamin-related protein 2 required for endocytosis of the plant pattern recognition receptor FLS2. PLoS One 10:e0137071. https://doi. org/10.1371/journal.pone.0137071

Choi SW, Tamaki T, Ebine K, Uemura T, Ueda T, Nakano A (2013) RABA members act in distinct steps of subcellular trafficking of the FLAGELLIN SENSING2 receptor. Plant Cell 25:1174-1187. https://doi.org/10.1105/tpc.112.108803

Chow CM, Neto H, Foucart C, Moore I (2008) Rab-A2 and Rab-A3 GTPases define a trans-Golgi endosomal membrane domain in Arabidopsis that contributes substantially to the cell plate. Plant Cell 20:101-123

Davenport NR, Sonnemann KJ, Eliceiri KW, Bement WM (2016) Membrane dynamics during cellular wound repair. Mol Biol Cell 27:2272-2285

Dettmer J, Hong-Hermesdorf A, Stierhof YD, Schumacher K (2006) Vacuolar $\mathrm{H}^{+}$-ATPase activity is required for endocytic and secretory trafficking in Arabidopsis. Plant Cell 18:715-730. https://doi.org/ 10.1105/tpc. 105.037978

Doherty GJ, McMahon HT (2009) Mechanisms of endocytosis. Annu Rev Biochem 78:857-902. https://doi.org/10.1146/annurev. biochem.78.081307.110540

Elkin SR, Oswald NW, Reed DK, Mettlen M, MacMillan JB, Schmid SL (2016) Ikarugamycin: a natural product inhibitor of clathrinmediated endocytosis. Traffic 17:1139-1149. https://doi.org/10. $1111 /$ tra. 12425

Emans N, Zimmermann S, Fischer R (2002) Uptake of a fluorescent marker in plant cells is sensitive to brefeldin A and wortmannin. Plant Cell 14:71-86. https://doi.org/10.1105/tpc.010339

Etxeberria E, Baroja-Fernandez E, Munoz FJ (2005) Pozueta-Romero J. Sucrose-inducible endocytosis as a mechanism for nutrient uptake in heterotrophic plant cells Plant Cell Physiol 46:474-481. https://doi. org/10.1093/pcp/pci044

Etxeberria E, Gonzalez P, Baroja-Fernández E, Romero JP (2006) Fluid phase endocytic uptake of artificial nano-spheres and fluorescent quantum dots by sycamore cultured cells. Plant Signal Behav 1: 196-200. https://doi.org/10.4161/psb.1.4.3142

Etxeberria E, Gonzalez P, Pozueta-Romero J (2007a) Mannitol-enhanced, fluid-phase endocytosis in storage parenchyma cells of celery (Apium graveolens; Apiaceae) petioles. Am J Bot 94:10411045

Etxeberria E, Gonzalez P, Pozueta J (2007b) Fluid-phase endocytosis in Citrus juice cells is independent from vacuolar $\mathrm{pH}$ and inhibited by chlorpromazine, an inhibitor of PI-3 kinases and clathrin-mediated endocytosis. J Hortic Sci Biotechnol 82:900-907. https://doi.org/10. 1080/14620316.2007.11512324

Etxeberria E, Gonzalez P, Pozueta J (2009) Evidence for two endocytic transport pathways in plant cells Plant Sci 177:341-348. https://doi. org/10.1016/j.plantsci.2009.06.014

Etxeberria E, Pozueta-Romero J, Fernández EB (2012) Fluid-phase endocytosis in plant cells. In: Samaj J (ed) Endocytosis in plants. Springer, Berlin Heidelberg, pp 107-122. https://doi.org/10.1007/ 978-3-642-32463-5 5

Fan LS, Li RL, Pan JW, Ding ZJ, Lin JX (2015) Endocytosis and its regulation in plants. Trends Plant Sci 20:388-397. https://doi.org/ 10.1016/j.tplants.2015.03.014

Foissner I (1991) Induction of exocytosis in characean internodal cells by locally restricted application of chlortetracycline and the effect of cytochalasin-b, depolarizing and hyperpolarizing agents. Plant Cell Environ 14:907-915. https://doi.org/10.1111/j.1365-3040.1991. tb00959.x

Foissner I, Wasteneys GO (2000) Microtubule disassembly enhances reversible cytochalasin-dependent disruption of actin bundles in characean internodes. Protoplasma 214:33-44. https://doi.org/10. 1007/BF02524260

Foissner I, Wasteneys GO (2007) Wide-ranging effects of eight cytochalasins and latrunculin a and B on intracellular motility and actin filament reorganization in characean internodal cells. Plant Cell Physiol 48:585-597. https://doi.org/10.1093/pcp/pcm030

Foissner I, Wasteneys GO (2012) The characean internodal cell as a model system for studying wound healing. J Microsc 247:10-22. https://doi.org/10.1111/j.1365-2818.2011.03572.x

Foissner I, Wasteneys GO (2014) Characean internodal cells as a model system for the study of cell organization. In: Kwang WJ (ed) International review of cell and molecular biology, vol 311. Academic Press, Burlington, pp 307-364

Foissner I, Sommer A, Hoeftberger M, Hoepflinger MC, Absolonova M (2016) Is wortmannin-induced reorganization of the trans-Golgi network the key to explain charasome formation? Front Plant Sci 7: 756. https://doi.org/10.3389/fpls.2016.00756

Franceschi VR, Lucas WJ (1980) Structure and possible function(s) of charasomes - complex plasmalemma-cell wall elaborations present in some characean species. Protoplasma 104:253-271. https://doi. org/10.1007/Bf01279771

French AP, Mills S, Swarup R, Bennett MJ, Pridmore TP (2008) Colocalization of fluorescent markers in confocal microscope images of plant cells. Nat Protoc 3:619-628. https://doi.org/10.1038/ nprot.2008.31

Gall L, Stan RC, Kress A, Hertel B, Thiel G, Meckel T (2010) Fluorescent detection of fluid phase endocytosis allows for in vivo estimation of endocytic vesicle sizes in plant cells with subdiffraction accuracy. Traffic 11:548-559. https://doi.org/10.1111/j. 1600-0854.2010.01037.x

Geldner N, Friml J, Stierhof Y-D, Jürgens G, Palme K (2001) Auxin transport inhibitors block PIN1 cycling and vesicle trafficking. Nature 413:425-428. https://doi.org/10.1038/35096571

Geldner N, Hyman DL, Wang X, Schumacher K, Chory J (2007) Endosomal signaling of plant steroid receptor kinase BRI1. Genes Dev 21:1598-1602. https://doi.org/10.1101/gad.1561307

Gendre D, Jonsson K, Boutte Y, Bhalerao RP (2015) Journey to the cell surface - the central role of the trans-Golgi network in plants. Protoplasma 252:385-398. https://doi.org/10.1007/s00709-0140693-1

Grebe M, Xu J, Möbius W, Ueda T, Nakano A, Geuze HJ, Rook MB, Scheres B (2003) Arabidopsis sterol endocytosis involves actinmediated trafficking via ARA6-positive early endosomes. Curr Biol 13:1378-1387

Gu Y, Zavaliev R, Dong X (2017) Membrane trafficking in plant immunity. Mol Plant 10:1026-1034. https://doi.org/10.1016/j.molp.2017. 07.001

Hasumi K, Shinohara C, Naganuma S, Endo A (1992) Inhibition of the uptake of oxidized low-density-lipoprotein in macrophage-J774 by the antibiotic ikarugamycin. Eur J Biochem 205:841-846. https:// doi.org/10.1111/j.1432-1033.1992.tb16848.x

Hause G, Samaj J, Menzel D, Baluska F (2006) Fine structural analysis of brefeldin A-induced compartment formation after high-pressure freeze fixation of maize root epidermis: compound exocytosis resembling cell plate formation during cytokinesis. Plant Signal Behav 1:134-139

Heyman NS, Burt JM (2008) Hindered diffusion through an aqueous pore describes invariant dye selectivity of $\mathrm{Cx} 43$ junctions. Biophys J 94 : 840-854. https://doi.org/10.1529/biophysj.107.115634

Hoepflinger MC, Geretschlaeger A, Sommer A, Hoeftberger M, Nishiyama T, Sakayama H, Hammerl P, Tenhaken R, Ueda T, Foissner I (2013) Molecular and biochemical analysis of the first ARA6 homologue, a RAB5 GTPase, from green algae. J Exp Bot 64:5553-5568. https://doi.org/10.1093/jxb/ert322

Hoepflinger MC, Geretschlaeger A, Sommer A, Hoeftberger M, Hametner C, Ueda T, Foissner I (2015) Molecular analysis and 
localization of CaARA7 a conventional RAB5 GTPase from characean algae. Traffic 16:534-554. https://doi.org/10.1111/tra. 12267

Hoepflinger MC, Hoeftberger M, Sommer A, Hametner C, Foissner I (2017) Clathrin in Chara australis: molecular analysis and involvement in charasome degradation and constitutive endocytosis. Front Plant Sci 8. https://doi.org/10.3389/fpls.2017.00020

Howard AC, McNeil AK, McNeil PL (2011) Promotion of plasma membrane repair by vitamin E. Nature Comm 2:597

Illes P, Schlicht M, Pavlovkin J, Lichtscheidl I, Baluska F, Ovecka M (2006) Aluminium toxicity in plants: internalization of aluminium into cells of the transition zone in Arabidopsis root apices related to changes in plasma membrane potential, endosomal behaviour, and nitric oxide production. J Exp Bot 57:4201-4213. https://doi.org/10. 1093/jxb/erl197

Irani NG, Russinova E (2009) Receptor endocytosis and signaling in plants. Curr Opin Plant Biol 12:653-659. https://doi.org/10.1016/j. pbi.2009.09.011

Jaillais Y, Fobis-Loisy I, Miege C, Rollin C, Gaude T (2006) AtSNX1 defines an endosome for auxin-carrier trafficking in Arabidopsis. Nature 443:106-109. https://doi.org/10.1038/nature05046

Jelinkova A et al (2010) Probing plant membranes with FM dyes: tracking, dragging or blocking? Plant J 61:883-892. https://doi.org/10. 1111/j.1365-313X.2009.04102.x

Kamitsubo E (1972) Window technique for detailed observation of characean cytoplasmic streaming. Exp Cell Res 74:613-616. https://doi.org/10.1016/0014-4827(72)90430-2

Kang B-H (2014) Shrinkage and fragmentation of thetrans-Golgi network in non-meristematic plant cells. Plant Signal Behav 6:884-886. https://doi.org/10.4161/psb.6.6.15305

Klima A, Foissner I (2008) FM dyes label sterol-rich plasma membrane domains and are internalized independently of the cytoskeleton in characean internodal cells. Plant Cell Physiol 49:1508-1521. https:// doi.org/10.1093/pcp/pcn122

Klima A, Foissner I (2011) Actin-dependent deposition of putative endosomes and endoplasmic reticulum during early stages of wound healing in characean internodal cells. Plant Biol 13:590-601. https:// doi.org/10.1111/j.1438-8677.2010.00413.x

Lam SK, Siu CL, Hillmer S, Jang S, An GH, Robinson DG, Jiang LW (2007) Rice SCAMP1 defines clathrin-coated, trans-Golgi-located tubular-vesicular structures as an early endosome in tobacco BY-2 cells. Plant Cell 19:296-319

Lam SK, Cai Y, Tse YC, Wang J, Law AHY, Pimpl P, Chan HYE, Xia J, Jiang L (2009) BFA-induced compartments from the Golgi apparatus and trans-Golgi network/early endosome are distinct in plant cells. Plant J 60:865-881. https://doi.org/10.1111/j.1365-313X. 2009.04007.x

Lee G-J, Sohn EJ, Lee MH, Hwang I (2004) The Arabidopsis Rab5 homologs Rha1 and Ara7 localize to the prevacuolar compartment. Plant Cell Physiol 45:1211-1220. https://doi.org/10.1093/pcp/ pch142

Li R, Liu P, Wan Y, Chen T, Wang Q, Mettbach U, Baluška F, Šamaj J, Fang X, Lucas WJ, Lin J (2012) A membrane microdomainassociated protein, Arabidopsis Flot1, is involved in a clathrinindependent endocytic pathway and is required for seedling development. Plant Cell 24:2105-2122. https://doi.org/10.1105/tpc.112. 095695

Lundmark R, Carlsson SR (2010) Driving membrane curvature in clathrin-dependent and clathrin-independent endocytosis. Semin Cell Dev Biol 21:363-370. https://doi.org/10.1016/j.semcdb.2009. 11.014

Luo T, Fredericksen BL, Hasumi K, Endo A, Garcia JV (2001) Human immunodeficiency virus type 1 Nef-induced CD4 cell surface downregulation is inhibited by ikarugamycin. J Virol 75:24882492. https://doi.org/10.1128/JVI.75.5.2488-2492.2001
Luo Y, Scholl S, Doering A, Zhang Y, Irani NG, di Rubbo S, Neumetzler L, Krishnamoorthy P, van Houtte I, Mylle E, Bischoff V, Vernhettes S, Winne J, Friml J, Stierhof YD, Schumacher K, Persson S, Russinova E (2015) V-ATPase activity in the TGN/EE is required for exocytosis and recycling in Arabidopsis. Nat Plants 1:15094. https://doi.org/10.1038/nplants.2015.94

Marg A, Schoewel V, Timmel T, Schulze A, Shah C, Daumke O, Spuler S (2012) Sarcolemmal repair is a slow process and includes EHD2. Traffic 13:1286-1294. https://doi.org/10.1111/j.1600-0854.2012. 01386.x

Martiniere A et al (2013) In vivo intracellular pH measurements in tobacco and Arabidopsis reveal an unexpected $\mathrm{pH}$ gradient in the endomembrane system. Plant Cell 25:4028-4043. https://doi.org/ $10.1105 /$ tpc. 113.116897

Meckel T, Hurst AC, Thiel G, Homann U (2004) Endocytosis against high turgor: intact guard cells of Vicia faba constitutively endocytose fluorescently labelled plasma membrane and GFPtagged $\mathrm{K}^{+}$-channel KAT1. Plant J 39:182-193

Moscatelli A, Ciampolini F, Rodighiero S, Onelli E, Cresti M, Santo N, Idilli A (2007) Distinct endocytic pathways identified in tobacco pollen tubes using charged nanogold. J Cell Sci 120:3804-3819

Naramoto S, Otegui MS, Kutsuna N, de Rycke R, Dainobu T, Karampelias M, Fujimoto M, Feraru E, Miki D, Fukuda H, Nakano A, Friml J (2014) Insights into the localization and function of the membrane trafficking regulator GNOM ARF-GEF at the Golgi apparatus in Arabidopsis. Plant Cell 26:3062-3076. https:// doi.org/10.1105/tpc.114.125880

Narasimhan M, Johnson A, Prizak R, Kaufmann WA, Casillas-Pérez B, Friml J (2020) Evolutionary unique mechanistic framework of clathrin-mediated endocytosis in plants. eLife 9:e52067. https:// doi.org/10.7554/eLife.52067

Newcomb EH (1980) Coated vesicles: their occurrence in different plant cell types. In: Ockleford C, Whyte A (eds) Coated vesicles. Cambridge University Press, Cambridge, London, New York, New Rochelle, Melbourne, Sydney, pp 55-68

Onelli E, Prescianotto-Baschong C, Caccianiga M, Moscatelli A (2008) Clathrin-dependent and independent endocytic pathways in tobacco protoplasts revealed by labelling with charged nanogold. J Exp Bot 59:3051-3068. https://doi.org/10.1093/jxb/ern154

Oparka KJ (1991) Uptake and compartmentation of fluorescent-probes by plant-cells. J Exp Bot 42:565-579. https://doi.org/10.1093/jxb/ 42.5.565

Oparka KJ, Prior DAM (1988) Movement of Lucifer yellow CH in potato-tuber storage tissues - a comparison of symplastic and apoplastic transport. Planta 176:533-540. https://doi.org/10.1007/ Bf00397661

Palocci C, Valletta A, Chronopoulou L, Donati L, Bramosanti M, Brasili E, Baldan B, Pasqua G (2017) Endocytic pathways involved in PLGA nanoparticle uptake by grapevine cells and role of cell wall and membrane in size selection. Plant Cell Rep 36:1917-1928. https://doi.org/10.1007/s00299-017-2206-0

Pickett-Heaps J (1967) Ultrastructure and differentiation in Chara sp. I. Vegetative cells. Austr J Biol Sci 20:539-552

Ravikumar R, Kalbfuß N, Gendre D, Steiner A, Altmann M, Altmann S, Rybak K, Edelmann H, Stephan F, Lampe M, Facher E, Wanner G, Falter-Braun P, Bhalerao RP, Assaad FF (2018) Independent yet overlapping pathways ensure the robustness and responsiveness of trans-Golgi network functions in Arabidopsis. Dev 145(21): dev169201. https://doi.org/10.1242/dev.169201

Reynolds GD, Wang C, Pan J, Bednarek SY (2018) Inroads into internalization: five years of endocytic exploration. Plant Physiol 176(1): 208-218. https://doi.org/10.1104/pp.17.01117

Rink J, Ghigo E, Kalaidzidis Y, Zerial M (2005) Rab conversion as a mechanism of progression from early to late endosomes. Cell 122: 735-749. https://doi.org/10.1016/j.cell.2005.06.043 
Robinson DG, Milliner S (1990) Endocytosis in plants. Physiol Plant 79: 96-104. https://doi.org/10.1111/j.1399-3054.1990.tb05871.x

Robinson DG, Neuhaus JM (2016) Receptor-mediated sorting of soluble vacuolar proteins: myths, facts, and a new model. J Exp Bot 67: 4435-4449. https://doi.org/10.1093/jxb/erw222

Robinson DG, Pimpl P (2014) Clathrin and post-Golgi trafficking: a very complicated issue. Trends Plant Sci 19:134-139. https://doi.org/10. 1016/j.tplants.2013.10.008

Rodal SK, Skretting G, Garred O, Vilhardt F, van Deurs B, Sandvig K (1999) Extraction of cholesterol with methyl-beta-cyclodextrin perturbs formation of clathrin-coated endocytic vesicles. Mol Biol Cell 10:961-974

Rodriguez-Furlan C, Minina EA, Hicks GR (2019) Remove, recycle, degrade: regulating plasma membrane protein accumulation. Plant Cell 31(12):2833-2854. https://doi.org/10.1105/tpc.19.00433

Rosquete MR, Davis DJ, Drakakaki G (2018) The plant trans-Golgi network: not just a matter of distinction. Plant Physiol 176(1):187-198. https://doi.org/10.1104/pp.17.01239

Salzman NH, Maxfield FR (1988) Intracellular fusion of sequentially formed endocytic compartments. J Cell Biol 106:1083-1091

Salzman NH, Maxfield FR (1989) Fusion accessibility of endocytic compartments along the recycling and lysosomal endocytic pathways in intact cells. J Cell Biol 109:2097-2104

Satiat-Jeunemaitre B, Hawes C (1992) Redistribution of a Golgi glycoprotein in plant cells treated with brefeldin a. J Cell Sci 103:11531166

Scheuring D, Viotti C, Krüger F, Künzl F, Sturm S, Bubeck J, Hillmer S, Frigerio L, Robinson DG, Pimpl P, Schumacher K (2011) Multivesicular bodies mature from the trans-Golgi network/early endosome in Arabidopsis. Plant Cell 23:3463-3481. https://doi. org/10.1105/tpc. 111.086918

Schmoelzer PM, Höftberger M, Foissner I (2011) Plasma membrane domains participate in ph banding of Chara internodal cells. Plant Cell Physiol 52:1274-1288. https://doi.org/10.1093/pcp/pcr074

Shepherd VA, Shimmen T, Beilby MJ (2001) Mechanosensory ion channels in Chara: the influence of cell turgor pressure on touch- activated receptor potentials and action potentials. Funct Plant Biol 28:551-566. https://doi.org/10.1071/PP01035

Stewart WW (1981) Lucifer dyes-highly fluorescent dyes for biological tracing. Nature 292:17-21

Stierhof YD, Viotti C, Scheuring D, Sturm S, Robinson DG (2013) Sorting nexins 1 and 2a locate mainly to the TGN. Protoplasma 250:235-240. https://doi.org/10.1007/s00709-012-0399-1

Takac $\mathrm{T}$ et al (2012) Wortmannin treatment induces changes in Arabidopsis root proteome and post-Golgi compartments. J Proteome Res 11:3127-3142. https://doi.org/10.1021/pr201111n

Tanchak MA, Fowke LC (1987) The morphology of multivesicular bodies in soybean protoplasts and their role in endocytosis. Protoplasma 138:173-182. https://doi.org/10.1007/Bf01281026

Toyooka K, Goto Y, Asatsuma S, Koizumi M, Mitsui T, Matsuoka K (2009) A mobile secretory vesicle cluster involved in mass transport from the Golgi to the plant cell exterior. Plant Cell 21(4):1212-1229

Tse YC, Lo SW, Hillmer S, Dupree P, Jiang L (2006) Dynamic response of prevacuolar compartments to brefeldin a in plant cells. Plant Physiol 142:1442-1459. https://doi.org/10.1104/pp.106.090423

Ueda T, Yamaguchi M, Uchimiya H, Nakano A (2001) Ara6, a plantunique novel type Rab GTPase, functions in the endocytic pathway of Arabidopsis thaliana. EMBO J 20:4730-4741. https://doi.org/10. 1093/emboj/20.17.4730

Ueda T, Uemura T, Sato MH, Nakano A (2004) Functional differentiation of endosomes in Arabidopsis cells. Plant J 40:783-789

Wang J, Cai Y, Miao Y, Lam SK, Jiang L (2009) Wortmannin induces homotypic fusion of plant prevacuolar compartments. J Exp Bot 60: 3075-3083. https://doi.org/10.1093/jxb/erp136

Wang LH, Li J, Zhou Q, Yang G, Ding XL, Li X, Cai CX, Zhang Z, Wei HY, Lu TH, Deng XW, Huang XH (2014) Rare earth elements activate endocytosis in plant cells. Proc Natl Acad Sci U S A 111: 12936-12941. https://doi.org/10.1073/pnas.1413376111

Publisher's note Springer Nature remains neutral with regard to jurisdictional claims in published maps and institutional affiliations. 